Türkiye Jeoloji Bülteni
Geological Bulletin of Turkey
$61(2018) 269-290$
doi: $10.25288 /$ tjb.459774

\title{
Aliağa (İzmir) Kıyılarında Termal Su Kaynaklarının Meiobentik Topluluğa (Bentik Foraminifer, Ostrakod ve Mollusk) Etkisi
}

The effects of submarine springs on meiobenthic assemblages (benthic foraminifers, ostracods and molluscs) on the coasts of Aliağa (İzmir)

\section{Engin Meriç¹ ${ }^{1}$, Atike Nazik² ${ }^{D}$, M. Baki Yokeş³ ${ }^{D}$, İpek F. Barut ${ }^{* 4}$ D, Mustafa Kumral $^{5}$ D, Mustafa Eryılmaz ${ }^{6}$ D, Fulya Yücesoy-Eryılmaz ${ }^{6}$ (D, İbrahim Gündoğan ${ }^{7}$, D Bora Sonuvar ${ }^{8}$ D, Feyza Dinçer ${ }^{9} \mathbb{D}$}

\author{
${ }^{1}$ Moda Hüseyin Bey Sokak No: 15/4, 34710 Kadıköy, Istanbul \\ ${ }^{2}$ Çukurova Üniversitesi, Mühendislik-Mimarlık Fakültesi Jeoloji Mühendisliği Bölümü, \\ 01330, Balcall, Adana \\ ${ }^{3}$ Hanımefendi Sokak No:160/9 34384 Şişli İstanbul

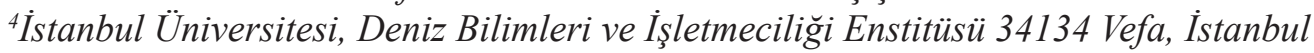 \\ 5ITÜ Maden Fakültesi Jeoloji Mühendisliği Bölümü, 80626 Maslak, İstanbul \\ ${ }^{6}$ Mersin Üniversitesi, Mühendislik Fakültesi, Jeoloji Mühendisliği Bölümü, 33343 Çiftlikköy, Mersin \\ ${ }^{7}$ Dokuz Eylül Üniversitesi, Mühendislik Fakültesi, Jeoloji Mühendisliği Bölümü, \\ Tinaztepe Kampusü, 35160, Buca, İzmir \\ ${ }^{8}$ Tramola Uluslararası Deniz Araştırma Hizmetleri İnş. Müh. ve Tic. Ltd. Şti., \\ 856 sokak No: 7/404, 35250, Konak, Izmir \\ ${ }^{9}$ Nevşehir Üniversitesi, Mühendislik ve Mimarlık Fakültesi, Jeoloji Mühendisliği Bölümü, \\ 50300 Nevşehir
}

Geliş/Received : 14.06.2018 • Düzeltilmiş Metin Geliş/Revised Manuscript Received : 20.08.2018 • Kabul/Accepted : 27.08.2018 • Bask1/Printed : 17.09 .2018 Araştırma Makalesi/Research Article Türkije Jeol. Bül. / Geol. Bull. Turkey

Öz: Doğu Ege Denizi kıyılarında eski ve yeni termal kaynakların bulunduğu alanlardaki yaşamda değişiklikler ile ilgili olarak farklı canlı toplulukları üzerinde birçok bilimsel çalışma sürdürülmektedir. Aliağa (İzmir) bölgesinde de termal kaynaklar bulunmaktadır. Birbirine yakın iki kaynak, Aliağa kuzeybatısı ile Karaağaç Koyu kuzeybatısı arasındaki Ilıca Burnu kıyı alanındadır. Sıcaklıkları sırasıyla $40^{\circ} \mathrm{C}$ ve $51{ }^{\circ} \mathrm{C}$ dir. Çalışma alanında yer alan deniz tabanı çökellerini kaya parçaları, çakı1, kum, silt ve kil birimleri oluşturmaktadır.

Bu araştırmada, Ilıca Burnu ile Taşlı Burun arasında kalan alanda deniz içinde farklı nokta ve derinliklerden alınmış olan 13 dip sediment örneği incelenmiştir. Sediment örneklerinde ICP-MS ile ağır metal analizleri yapılmıştır. Ayrıca, kaynak suyu ve deniz yüzeyinden alınan sularda eser element analizleri sonucu ile toplam Alfa ve Beta Özellikleri değerlendirilmiştir. Amaç, bu bölgede yer alan sıcak su kaynaklarının bentik foraminifer, ostrakod ve mollusk topluluklarına olan etkisini araştırarak meiobentik yaşam koşulları hakkında yorum yapmaktır.

Çalışılan örneklerde 32 cins ve 50 türden oluşan tipik Ege Denizi foraminifer faunasının baskın olduğu gözlenmiştir. Bu bölge için önemli bir özellik, çalışılan örneklerde, Ege Denizi Türkiye kıyılarında sıkça rastlanılan Amphistegina lobifera Larsen ile peneroplidlere ait herhangi bir cins ve türe ait fertlere rastlanılmamış olmasıdır. Ostrakodlardan Akdeniz ve Ege Denizi'nde yaygın olarak bilinen 19 cins ve 28 tür bulunmuştur. Mollusk faunasını ise gastropodlardan 9 cins ve 10 tür, bivalvlerden 14 cins ve 14 tür oluşturmaktadır.

Bulgulardan diğer önemli bir özellik ise, A11 numaralı örnekte gözlenen çok sayıda tekçe jips kristallerinin varlığıdır. Bu bulgu, eski bir termal kaynağın göstergesidir. Ayrıca, aynı örnekte ağır metallerden çinko ( $\mathrm{Zn})$, kurşun (Pb), bakır

*Yazışma / Correspondence: barutif@istanbul.edu.tr

(C) 2018 JMO Her hakkı saklıdır/All rights reserved http://tjb.jmo.org.tr http://dergipark.gov.tr/tjb 
$(\mathrm{Cu})$ ve arsenik (As) dağılımı en yüksek değerde bulunmuştur. Bu örneklerde foraminifer türleri az sayıda, ostrakod ve bivalvlerden ise birer tür saptanmıştır.

Anahtar Kelimeler: Aliağa (İzmir), dip sediment, Doğu Ege Denizi, jeokimya, Meiofauna, sıcak su.

\begin{abstract}
Many scientific researches have been done on different faunal assemblages in relation to the environmental condition from thermal sources located on the eastern Aegean Sea coast. Aliağa (İzmir) region has also thermal resources. These two thermal springs are closely located on the coast of Ilica Cape, northwest of Aliağa (İzmir) and northwest of Karaağaç Cove. Their temperatures are $40^{\circ} \mathrm{C}$ and $51^{\circ} \mathrm{C}$, respectively. The bottom deposits consist of rock fragments, gravel, sand, silt and clay units in the study area.
\end{abstract}

In this research, 13 bottom sediment samples taken from different points and corresponding depths in the sea between the Ilica Cape and the Tassl Cape were examined. Heavy metal analysis in the sediment samples were done by using ICP-MS. In addition, the results of trace element analysis and total Alpha and Beta features in the samples taken from the sea surface and spring waters were evaluated. The aim is to interpret meiobenthic living conditions by investigating on the effect of thermal springs the benthic foraminifera, ostracod and mollusk assemblages in this region.

It was observed that the typical Aegean Sea foraminifera fauna composed of 32 genera and 50 species predominated in the studied samples. An important peculiarity of the region is absence of amphistegina lobifera and peneroplid genera and species commonly observed in the Aegean coasts of Turkey. Widely known nineteen genera and twentyeight species from Ostracods were found in Mediterranean and Aegean Sea. Mollusc faunas consist of 9 genera and 10 species from gastropods, 14 genera and 14 species from bivalves.

The other an important finding in the deposits are the presence of numerous gypsum crystals in sample A11. This finding is an indication of an old thermal source. Furthermore, distribution of zinc ( $\mathrm{Zn}$ ), lead (Pb), Cooper (Cu) and arsenic (As) as the heavy metals in the same sample were found to be the highest. In these examples, a few species of foraminifera and only one species from ostracods and bivalves were found.

Keywords: Aliağa (İzmir), deep sediment, Eastern Aegean Sea, geochemistry, hotspring, Meiofauna.

\section{GíRiş}

Doğu Ege Denizi kıyılarında Biga Yarımadası'nın güneyinden itibaren Marmaris Körfezi'ne kadar ulaşan kıyı şeridinde çok sayıda termal mineralli su kaynağ 1 bulunmakta olup, bu kaynakların foraminiferler üzerine olan etkileri son yirmi yıldır detaylı olarak araştırılmaktadır (Meriç vd., 2009a). Bu araştırmalarda, Ege Denizi'nin kıyı alanlarında gözlenen deniz içi termal veya 1 lık su kaynakları çevresinde gelişen farklı ortamsal koşulların etkisiyle gelişen fiziksel ve kimyasal değişimler nedeniyle canlı yaşamında farklılıklar olduğu ortaya konmuştur (Meriç, 1986; Meriç vd., 2002a, b; Meriç vd., 2003a, b; Meriç vd., 2009a). Araştırma, Çandarlı Körfezi'nin güneyinde, batıda Ilıca Burnu ile doğuda Taşlı Burun arasında kalan bölgede yapılmıştır (Şekil 1). Bu bölgede, deniz tabanının ortalama eğimi \%1-4 arasında olup maksimum derinlik 39.00 metredir. İnceleme alanı batısında Aliağa Sahil Ilıcaları olarak adlandırılan Ilıca Burnu'nda iki sıcak su kaynağ 1 bulunmaktadır (Şekil 2). Bunlardan biri kıyıdaki bir mağara içinde yer alır. Su sıcaklığ $151^{\circ} \mathrm{C}$ olup 10 1/s debiye sahiptir. Diğeri ise, deniz düzeyinden yaklaşık $1.00 \mathrm{~m}$ yükseklikte bulunan bir diğer mağara içindedir. Su sıcaklığ $40^{\circ} \mathrm{C}$ ve debisi 2 1/s'dir (Filiz vd., 1997). Adı geçen kaynakların, Aliağa piroklastikleri biriminden, KB-GD yönlü faylara bağlı olarak gelişen tektonik oluşumlu bir mağaradan yüzeye ulaştıkları düşünülmektedir.

$\mathrm{Bu}$ çalışmada amaç, Ilıca Burnu ile Taşı Burun arasında kalan bölgedeki bu sıcak su kaynaklarının meiobentik (bentik foraminifer, ostrakod ve mollusk) topluluk üzerine olan etkisini araştırmaktır. 


\section{ALİAĞA KOYU VE YAKIN ÇEVRESINIIN OŞINOGRAFISİ VE GÜNCEL ÇÖKEL DAĞILIMI}

Aliağa Koyu, İzmir Körfezi kuzeyinde, batıda Taşlı Burun ile doğuda Kabakhisarı Burnu arasında yer alır. Ortalama eğimi \%1-4 arasındadır. Maksimum derinliği 33 metredir. Taşı Burun ile Kabakhisarı Burnu arası ise dar bir kanal şeklindedir (Şekil 1).

\section{Batimetri}

Ilıca Burnu-Aliağa Koyu-Kızıl Burun ile Tavşan Adası arasında kalan bölge, genel olarak sığ bir denizalanı olup 30.00-50.00 m arasında değişmekte ve ortalama derinlik $40.00 \mathrm{~m}$ civarındadır. Tavşan Adası güneyinden itibaren, Ilıca Burnu batısında kalan bölgede derinlik artarak 120 metrelere ulaşmaktadır. Kuzeydoğuda,

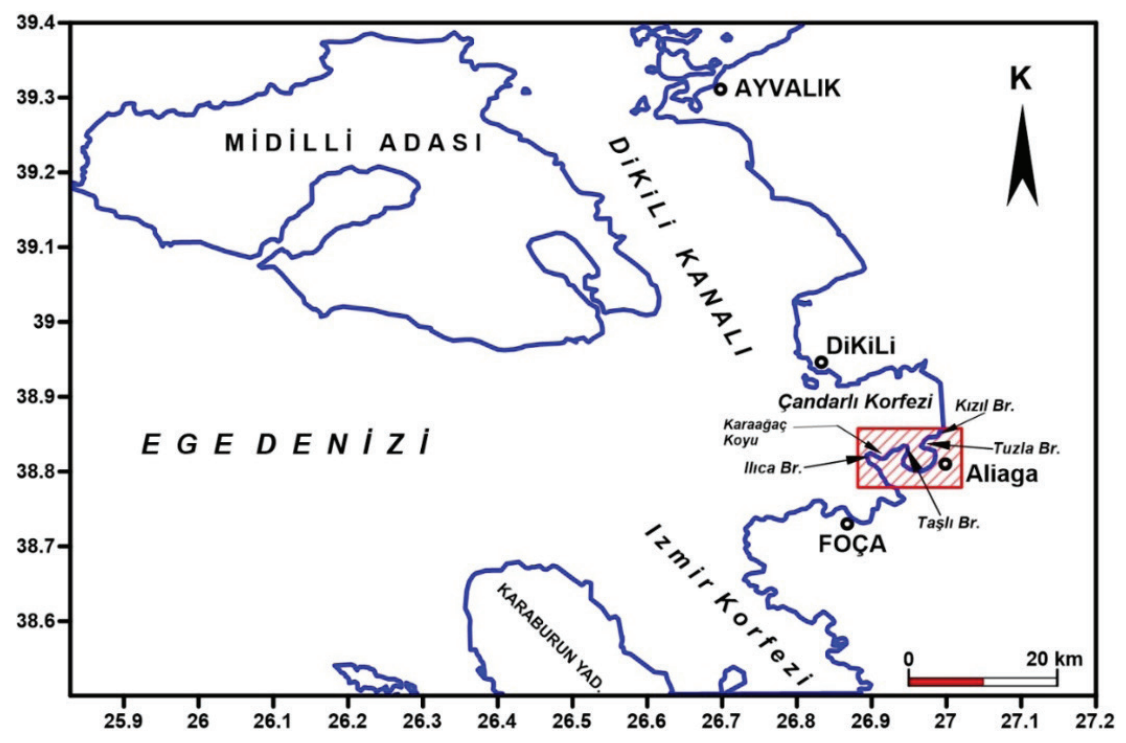

Şekil 1. Çalışma alanı yer bulduru haritası.

Figure 1. Location map of the study area.

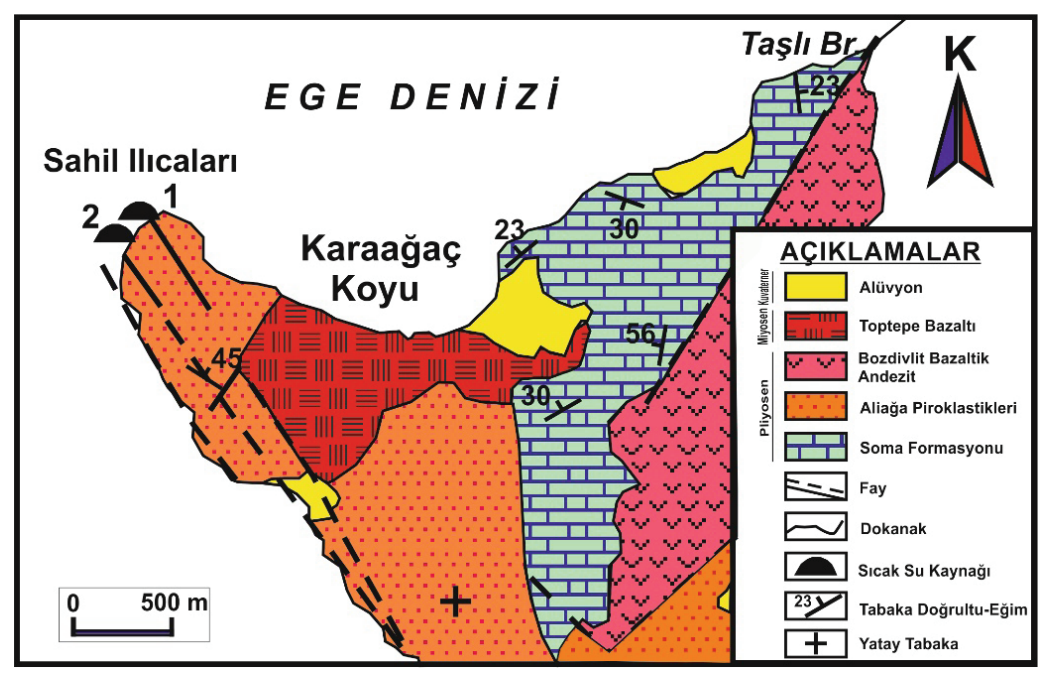

Şekil 2. Aliağa Ilıca Burnu termal sularının çıkış noktaları (Filiz vd., 1997).

Figure 2. Output points of thermal waters at the Aliağa Ilıca Cape (Filiz et al., 1997). 
Kızıl Burun açıklarında yaklaşık 50.00 m derinlik görülmektedir. Bu bölge, genel olarak tekdüze bir morfolojik yapı gösterir. Deniz tabanı oldukça düz ve kuzeye hafif eğimle 50.00 metreye ulaşır. Ilıca Burnu batısında bu eğim \%4'ü bulur (Şekil 3 ve 4).

Çalışma sahası içinde yer alan Aliağa Koyu, yaklaşık 1.4 km genişliğinde bir boğazla Çandarlı Körfezi'ne bağlanır. Dairesel görünüşlüdür (Şekil
3) ve çanak şeklinde bir denizaltı görünümüne sahiptir (Şekil 4). Uzunluğu $3.9 \mathrm{~km}$ ve genişliği 3.8 km'dir. Aliağa Koyu girişinden (KB) Aliağa ilçesine doğru (GD) ilerlendiğinde koyun taban morfolojisi, 5'er metrelik basamaklar şeklinde yükselir. Büyük bir kısmı 20.00 m'den sığdır. En derin yeri 25.00 metre olup koyun çıkış noktası boğazın ekseni üzerindedir. Buradan itibaren dış tarafa doğru derinlik artar ve 30.00 metreyi geçer (Şekil 3 ve 4).

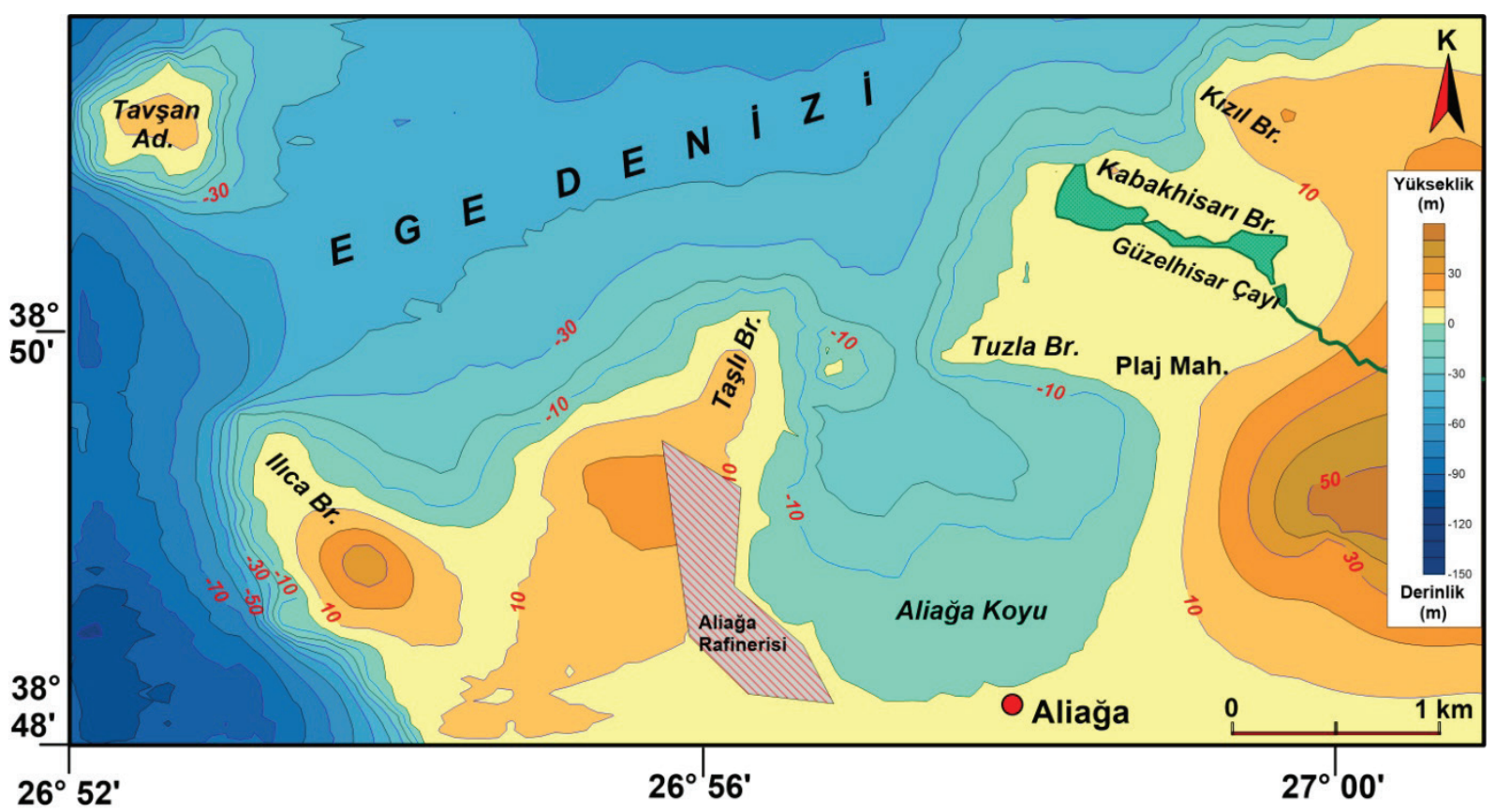

Şekil 3. Aliağa Koyu ve çevresinin batimetri haritası (derinlikler metredir).

Figure 3. The bathymetry map of Aliağa Bay and its surrounding (Depth is meter).

\section{Bölgenin Oşinografisi}

Ilıca Burnu-Kızıl Burun arasında ortalama yüzey suyu sıcaklığ 1 , ilkbaharda $16.42^{\circ} \mathrm{C}$, yazın $23.87^{\circ} \mathrm{C}$ sonbaharda $21.80^{\circ} \mathrm{C}$, kışın $14.03^{\circ} \mathrm{C}$ dir. Ortalama dip suyu sıcaklıkları ise ilkbaharda $14.42^{\circ} \mathrm{C}$, yaz mevsiminde $15.82^{\circ} \mathrm{C}$, sonbaharda $15.44^{\circ} \mathrm{C}$ ve kışın $13.69^{\circ} \mathrm{C}^{\prime} \operatorname{dir}($ Şekil 5a).
Bölgenin ortalama tuzluluk miktarları ise, ilkbahar mevsiminde yüzey suyunda \%038.97; $50.00 \mathrm{~m}$ su derinliğinde $\% 38.99$, yaz mevsiminde yüzey suyunda $\% 39.41,50.00 \mathrm{~m}$ su derinliğinde $\%$ 39.30; sonbaharda yüzey suyunda \%o38.92; $50.00 \mathrm{~m}$ su derinliğinde \%o38.67 ve k1şın yüzey suyunda \%o38.65, $50.00 \mathrm{~m}$ derinlikte \%o38.53 değerleri arasında değiştiği görülmektedir (Yücesoy-Eryılmaz vd., 2002, 2004, 2005) (Şekil $5 \mathrm{~b})$. 


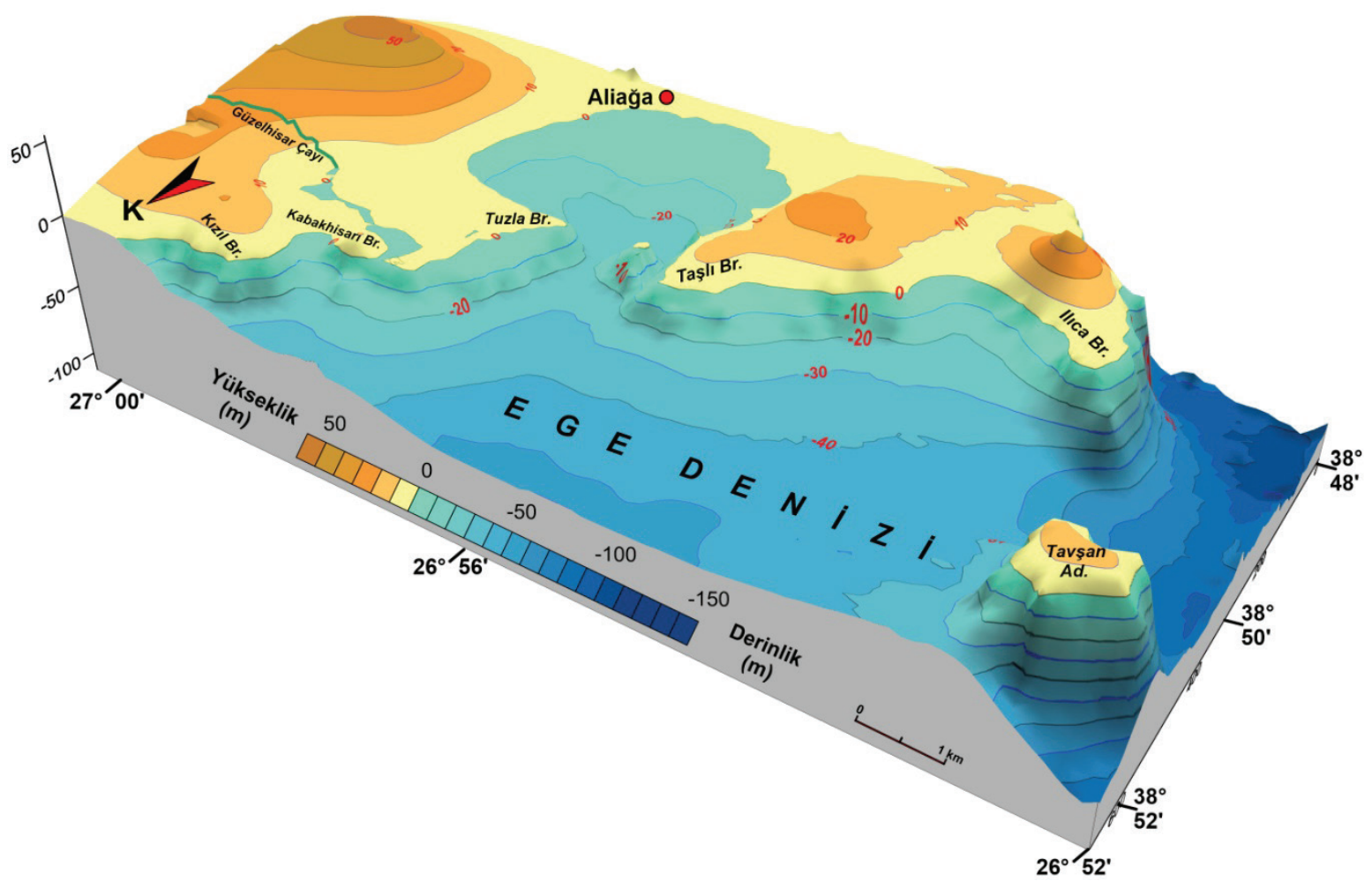

Şekil 4. Aliağa Koyu ve çevresi deniz tabanının morfolojik yapısı (derinlik ve yükseklikler metredir).

Figure 4. The morphological structure of sea floor at the Aliağa Bay and its surrounding (depth and height are meter).

Aliağa Koyu'nda ortalama yüzey suyu sıcaklığ i ilkbaharda $16.39^{\circ} \mathrm{C}$, yazın $23.76^{\circ} \mathrm{C}$, sonbaharda $21.61^{\circ} \mathrm{C}$, k1şın ise $21.61^{\circ} \mathrm{C}^{\prime}$ dir. Dip suyu sıcaklığ 1 ortalama ilkbaharda $14.24{ }^{\circ} \mathrm{C}$, Yazın $15.77^{\circ} \mathrm{C}$, sonbaharda $15.26^{\circ} \mathrm{C}$ ve kışın $13.39{ }^{\circ} \mathrm{C}^{\prime} \operatorname{dir}($ Şekil 6a).
Çalışma alanında, yüzey sularının sıcaklığ hava sıcaklığına bağlı olarak değişir. Yüzeyde en yüksek tuzluluk değeri ise \%o39.40'dır (yaz mevsimi). $20.00 \mathrm{~m}$ derinlikte ise tuzluluk fark1 en düşük \%038.58 (kış mevsimi), en yüksek ise \%039.25'dir. (yaz mevsimi). Bölgede tuzluluk fark1, yüzey ve alt tabakalar arasında, tüm mevsimlerde yok denecek kadar azdır (Şekil 6b). 


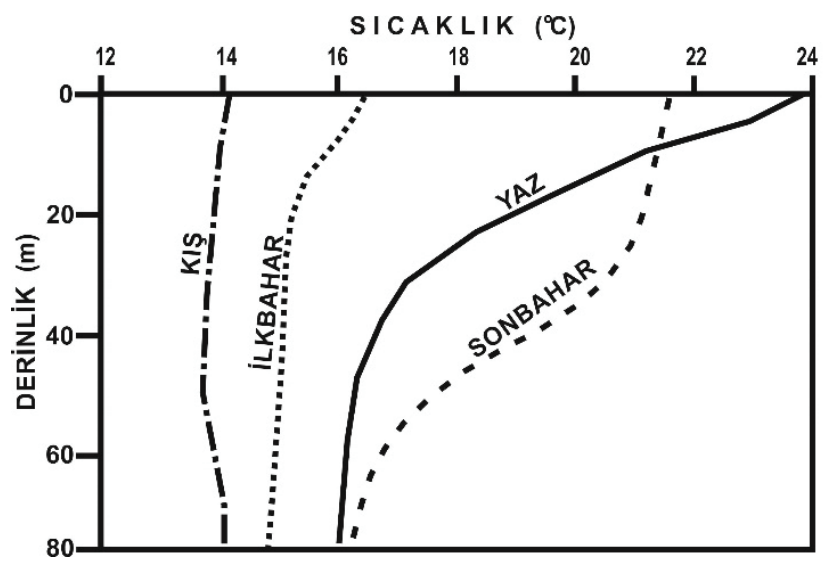

a

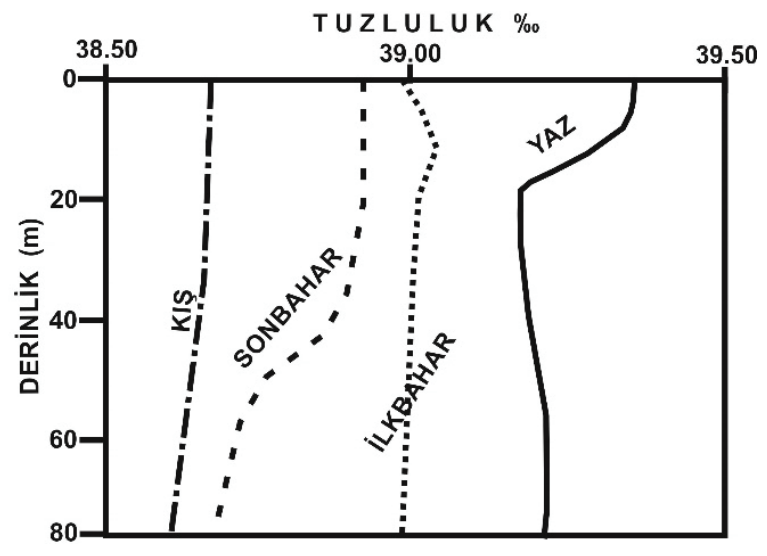

b

Şekil 5. Aliağa bölgesi, Ilıca Burnu-Kızıl Burun arası, mevsimsel ortalama sıcaklıkları (a) ve mevsimsel ortalama tuzlulukları (b).

Figure 5. Seasonal mean temperatures (a) and seasonal mean salinity values (b) between Ilıca and Kizll Capes at the Aliağa region.

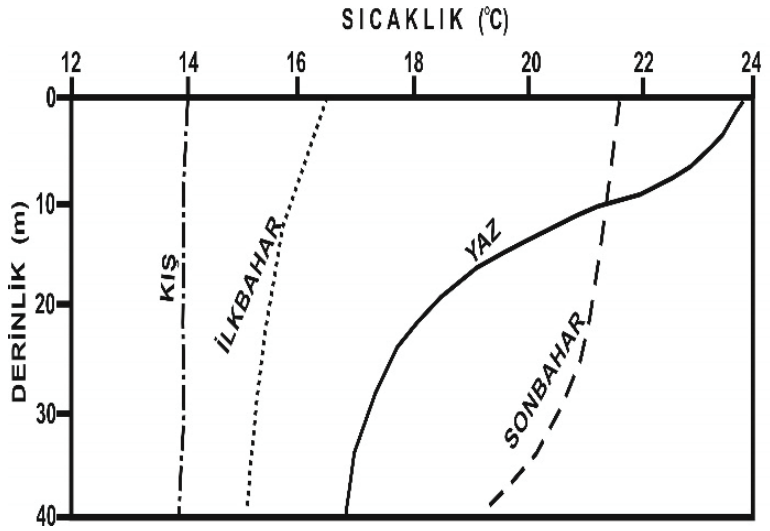

a

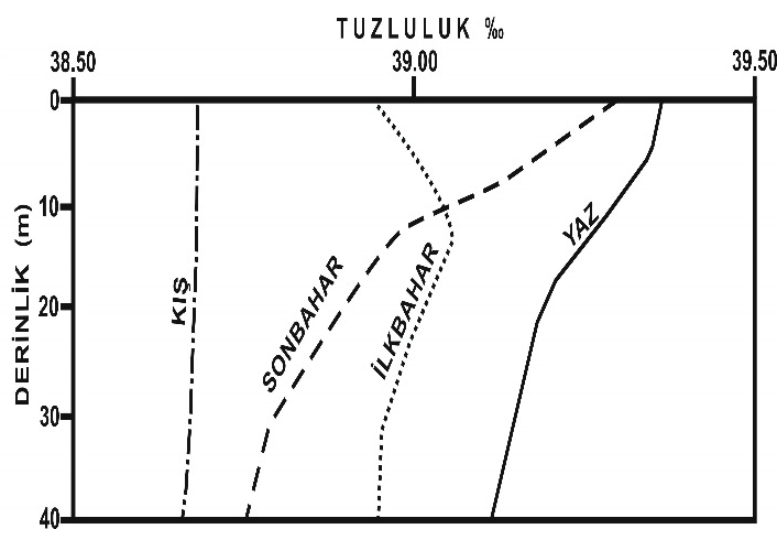

b

Şekil 6. Aliağa Koyu'nun, mevsimsel ortalama sıcaklıkları (a) ve tuzlulukları (b).

Figure 6. Seasonal mean temperatures (a) and salinity values (b) at Aliağa Bay.

Termoklin tabakasi yazın, $21^{\circ} \mathrm{C}^{\prime}$ den $(\sim-9.00$ m derinlikte) başlar ve $17-18^{\circ} \mathrm{C}$ 'de $(\sim-19.00 \mathrm{~m}$ derinlikte) dengelenir. 22.00 metre derinlikte alt su tabakasına geçilir (Eryılmaz ve YücesoyEryılmaz, 2001; Yücesoy-Eryılmaz, vd., 2005). Batı ve kuzey batı yönlerinden esen rüzgârlar, yüzeyde, kıyı şeridi boyunca yerel akıntılar oluşturmaktadır. Zaman zaman, batı yönünden esen güçlü rüzgarlar saat yönünün tersine yüzey akıntıları oluşturabilmektedir (Eryılmaz vd., 1999; Eryılmaz ve Yücesoy-Eryılmaz, 2012) .

\section{Çökel Dağılımı}

Çalışma alanının kıyı ve dip çökelleri, yerel akıntılar, dalgalar, karanın topografyası, denizaltı morfolojisi ve batimetrinin etkisi altındadır. Çalışma alanında yer alan çökeller, kaya parçaları, çak1l, kum, silt ve kil olmak üzere 5 farklı türdür (Şekil 7). Kumlu malzemeler, çakıllı kum, kum ve siltli kumdur. Siltli malzemeler ise silt, kumlu silt ve killi siltten oluşur. Bu bölgede genellikle tane boyu dağılımı kıyıdan derine doğru kaba taneliden 
ince taneliye geçiş yapmakta ve ince kıyı şeridine paralel olarak birbirine geçiş yapan bantlar halinde görülmektedir (Eryılmaz vd., 1999, 2017; Eryılmaz ve Yücesoy-Eryılmaz, 2012).

Genel olarak $10.00 \mathrm{~m}$ su derinliğine kadar kum ve siltli kum birimleri yer alır. $10.00 \mathrm{~m}$ derinlikten itibaren $20.00 \mathrm{~m}$ su derinliğinden 30.00 m'ye kadar yer yer kumlu silt ve kumlu camur birimleri görülür. Bu birimler özellikle burunların denize doğru çıkıntı yaptığı alan ile diğer yerlerde ince bantlar halindedir. Tavşan Adası-Ilıca Burnu hattının batısında kalan ve derinliği 80.00 m'yi aşan (yer yer 100.00 m'yi geçen) deniz alanı çamurlu malzeme ile kaplıdır. Tavşan Adası-Ilıca Burnu-Taşlı Burun arasında kalan ve derinliği 35.00 m'ye ulaşan kesimde geniş bir alanı siltli malzeme kaplamaktadır (Şekil 7).

Özellikle Aliağa Koyu'nun güney kesimlerinde su derinliği azdır. Burada kumlu birimler oldukça geniş bir alan oluşturur. Kıyı ile $5.00 \mathrm{~m}$ derinliğe kadar olan kesim kum birimi ile kaplıdır. $5.00 \mathrm{~m}$ ile $10.00 \mathrm{~m}$ derinlikler arasında siltli kum birimi görülür. $10.00 \mathrm{~m}$ derinlikten sonra, kumlu silt yaklaşık 15.00-16.00 m'lere kadar devam eder. 20.00 m'den itibaren yaygın olarak görülen silt birimidir. Çamurlu malzeme koyun ortasından itibaren çıkışına kadar devam etmektedir. Çalışma alanının en derin kısımlarında, dar bir alanda killi birim bulunur.
Tuzla Burnu ile Kızıl Burun arasında sı̆̆ kesimlerde kumlu birimler yer alırken 30.00 m'den derinlere doğru önce siltli birimler, ardından da çamurlu ve siltli birimler gözlenir. Siltli kil birimi $50.00 \mathrm{~m}$ ve daha derinlerde yayılım gösterir.

\section{MALZEME VE YÖNTEM}

Ilıca Burnu ile Taşlı Burun arasındaki alandan 1-11 Temmuz 1997 ve 12-13 Kasım 2001 tarihlerinde Seyir Hidrografi ve Oşinografi Dairesince 17.00-39.00 m derinliklerden alınmış olan 13 örnek foraminifer, ostrakod ve mollusk topluluğu açısından incelenmiştir (Şekil 8, Çizelge 1). Örneklerdeki belirtilen topluluğun güncel değişimlerinin gözlenmesi amacıyla Ilıca Burnu ile Taşlı Burun arası alanda farklı derinlik ve noktalardan yeniden örnekleme yapılması planlanmıştır. Fakat çalışılacak bölge Aliağa Petrol Rafinerisi alanı içinde kaldığından yetkililerden müsaade istenmişse de bu konuda olumlu cevap alınamamıştır. Ancak, güncel olarak deniz suyu (D1) ve deniz düzeyindeki mağara içi kaynak suyu (M1)'dan eser element analizi için örnekler alınmış ve radyoaktivite için alfa ve beta $(\mathrm{Bq} / \mathrm{l})$ okumaları gerçekleştirilmiştir. Sedimentlerin ağır metal analizleri İstanbul Teknik Üniversitesi'nde ICP-MS'te gerçekleştirilmiştir. 


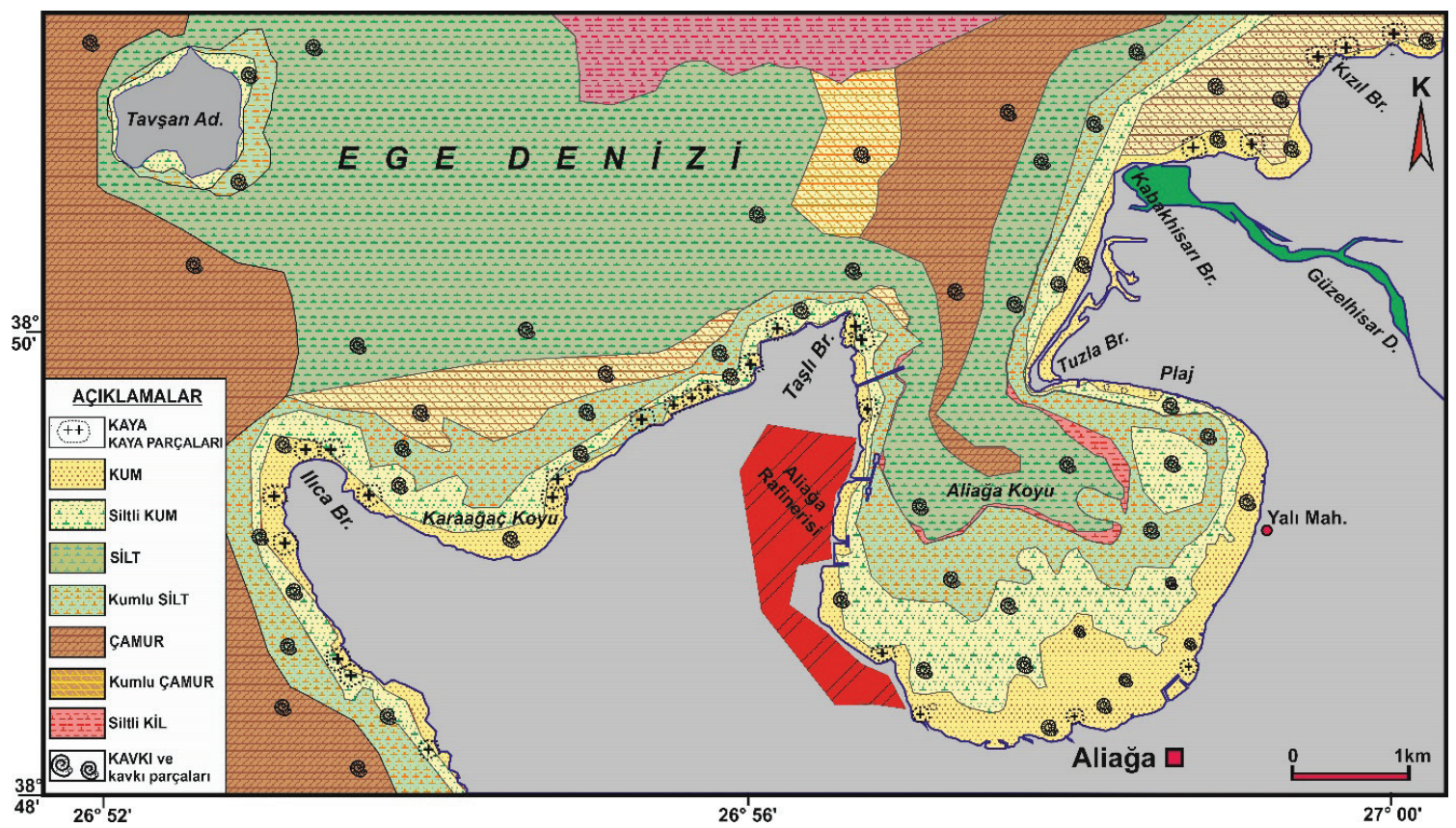

Şekil 7. Ilıca Burnu-Aliağa Koyu-kızıl Burun arası alanın güncel çökel dağılımı.

Figure 7. The distribution of recent sediment between Ilıca Cape-Aliağa Bay-Kızıl Cape.

Çizelge 1. Örnek noktaları koordinat ve derinlik değerleri.

Table 1. The Coordinates and depth values of sampling points.

\begin{tabular}{|c|c|c|c|}
\hline İst. No & Enlem & Boylam & $\begin{array}{c}\text { Derinlik } \\
\text { (m) }\end{array}$ \\
\hline A1 & $\mathrm{N} 38^{\circ} 49^{\prime} 50.0^{\prime \prime}$ & Е $26^{\circ} 54^{\prime} 36.0^{\prime \prime}$ & 39.00 \\
\hline A2 & N $38^{\circ} 49^{\prime} 59.0^{\prime \prime}$ & E $26^{\circ} 54^{\prime} 54.0^{\prime \prime}$ & 36.00 \\
\hline $\mathrm{A} 3$ & $\mathrm{~N} 38^{\circ} 50^{\prime} 10.0^{\prime \prime}$ & E $26^{\circ} 55^{\prime} 16.0^{\prime \prime}$ & 32.00 \\
\hline A4 & N $38^{\circ} 50^{\prime} 05.0^{\prime \prime}$ & E $26^{\circ} 55^{\prime} 24.0^{\prime \prime}$ & 32.00 \\
\hline A5 & $\mathrm{N} 38^{\circ} 49^{\prime} 53.0^{\prime \prime}$ & E $26^{\circ} 55^{\prime} 16.0^{\prime \prime}$ & 31.00 \\
\hline A6 & N $38^{\circ} 49^{\prime} 51.0^{\prime \prime}$ & E $26^{\circ} 54^{\prime} 53.0^{\prime \prime}$ & 36.00 \\
\hline A7 & $\mathrm{N} 38^{\circ} 49^{\prime} 24.0^{\prime \prime}$ & E $26^{\circ} 54^{\prime} 48.0^{\prime \prime}$ & 22.00 \\
\hline A8 & N $38^{\circ} 49^{\prime} 50.0^{\prime \prime}$ & E 265 54'46.0” & 28.00 \\
\hline A9 & N $38^{\circ} 50^{\prime} 00.0^{\prime \prime}$ & E $26^{\circ} 55^{\prime} 35.0^{\prime \prime}$ & 30.00 \\
\hline A10 & $\mathrm{N} 38^{\circ} 50^{\prime} 00.0^{\prime \prime}$ & E $26^{\circ} 55^{\prime} 35.0^{\prime \prime}$ & 28.00 \\
\hline A11 & $\mathrm{N} 38^{\circ} 49^{\prime} 20.0^{\prime \prime}$ & E $26^{\circ} 54^{\prime} 43.0^{\prime \prime}$ & 17.00 \\
\hline A12 & N $38^{\circ} 50^{\prime} 01.3^{\prime \prime}$ & E $26^{\circ} 54^{\prime} 12.0^{\prime \prime}$ & 33.00 \\
\hline A13 & N $38^{\circ} 50^{\prime} 37.8^{\prime \prime}$ & Е $26^{\circ} 56^{\prime} 00.7^{\prime \prime}$ & 32.00 \\
\hline
\end{tabular}

Çalışma alanında oşinografik parametrelerden CTD (sıcaklık, iletkenlik, tuzluluk, yoğunluk ve derinlik) kullanılarak yerinde mevsimsel olarak ölçülmüştür. Ayrıca 2 istasyonda mevsimsel akıntı ölçümleri de yapılmıştır. Akıntı hız ve yönleri 3 farklı derinlikte (yüzey, orta ve dipte) kısa süreli olarak ölçülmüştür. 56 istasyondan "Van Veen Grap" örnekleyiciler ile yüzey çökel örnekleri alınmıştır. Çökel örneklerine, elek ve 1slak analiz yöntemleri uygulanmış, çökeller tane büyüklüğüne göre sınıflandırılarak bölgenin 1:10.000 ölçekli çökel dağılım haritası hazırlanmıştır (Folk, 1974; Wentworth, 1922).

Sediment örneklerinde mikroorganizma analizleri Babin (1980) ve Bignot (1985)'e göre yapılmıştır. 5'er gr olarak tartılan kuru örneklerin üzerine \% 10'luk $\mathrm{H}_{2} \mathrm{O}_{2}$ eklenerek 24 saat bekletilmiş ve bunu takiben $0.063 \mathrm{~mm}$ 'lik elekte tazyikli su ile yıkanmış, $50{ }^{\circ} \mathrm{C}^{\prime}$ lik etüvde kurutulduktan sonra 2.00, 1.00, 0.500, 0.250, 0.125 mm'lik eleklerde elenmiştir. Bu örnekler binoküler mikroskopta incelenerek içermiş olduğu bentik foraminifer, ostrakod ve mollusklar ayırtlanmıştır. 


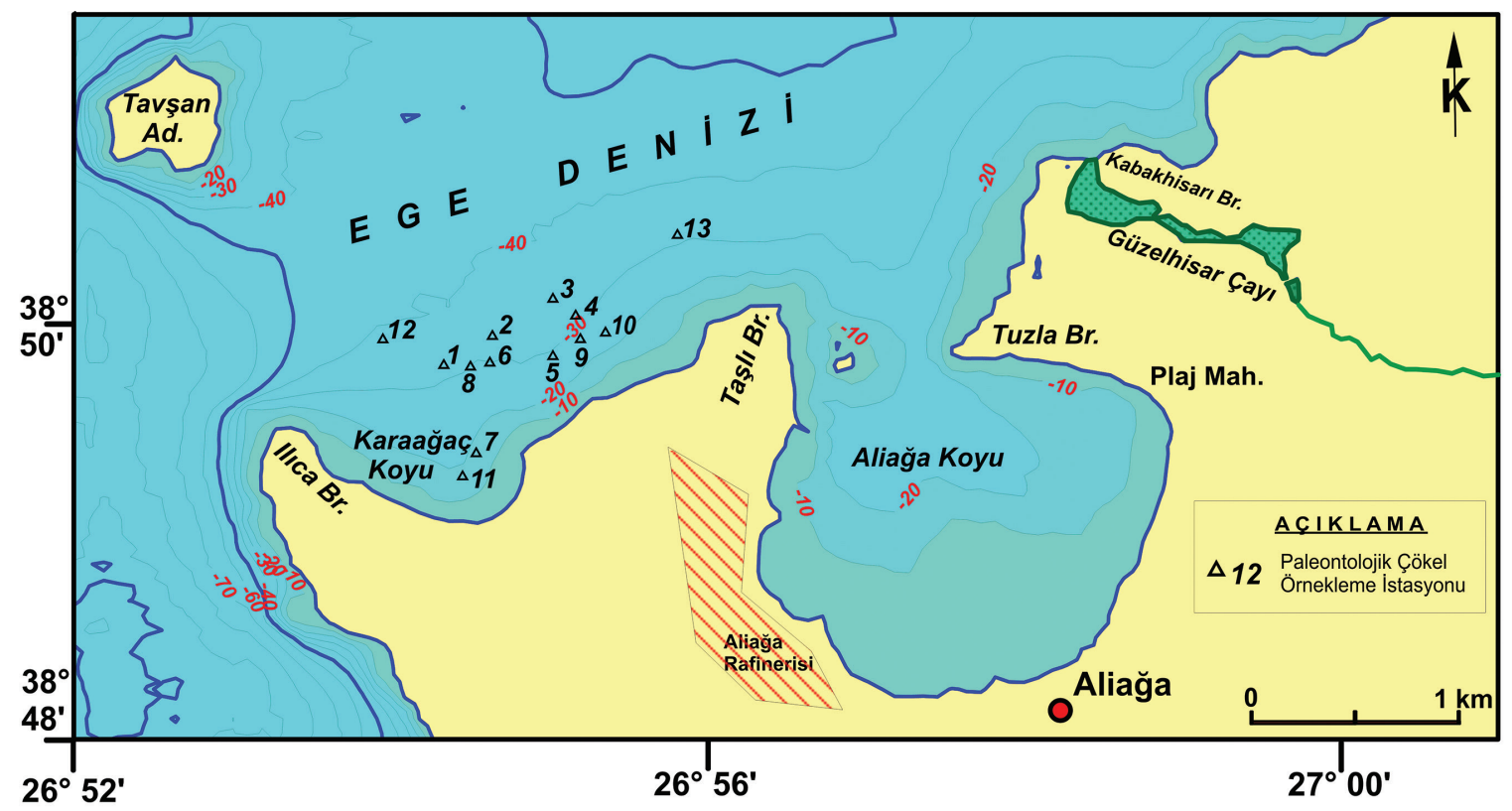

Şekil 8. Aliağa kıyıları ile Ilıca Burnu-Kızıl Burun arası örnekleme noktaları.

Figure 8. The sampling points between Aliağa coast and Ilıca Cape-Kızll Cape.

\section{ARAŞTIRMA BULGULARI}

\section{Mikro ve Makro Fauna Toplulukları}

\section{Bentik Foraminifer Topluluğu}

Bölgede gözlenen bentik foraminifer topluluğu tipik Ege Denizi faunal özelliğini taşımaktadır. Alınan 13 örnekten 13'ünde de foraminiferler bulunmaktadır. Bentik foraminiferler 52 tür ve 32 cins saptanmış olup, tipik Ege faunasının yanısıra Akdeniz'de gözlenen bazı cins ve türlere de rastlanmıştır. Bunlar Vertebralina striata d'Orbigny, Nubecularia lucifuga Defrance, Adelosina cliarensis (Heron-Allen ve Earland), A. duthiersi Schlumberger, A. mediterranensis (le Calvez J. ve Y.), A. partschi (d'Orbigny), Spiroloculina angulata d'Orbigny, S. angulosa Terquem, $S$. excavata d'Orbigny, $S$. ornata d'Orbigny, Siphonaperta aspera (d'Orbigny), Cycloforina contorta (d'Orbigny), Lachlanella bicornis (Walker ve Jacob), Massilina secans (d'Orbigny), Quinqueloculina berthelotiana d'Orbigny, Q, jugosa Cushman, Q. lamarckiana d'Orbigny, Q. seminula (Linné), Miliolinella labiosa (d'Orbigny), M. subrotunda (Montagu), Pseudotriloculina laevigata (d'Orbigny), $P$. rotunda (d'Orbigny), Pyrgo elongata (d'Orbigny), Triloculina marioni Schlumberger, T. tricarinata d'Orbigny, Welmanellinella striata (Sidebottom), Sigmoilinita costata (Schlumberger), Reussella spinulosa (Reuss), Valvulineria bradyana (Fornasini), Neoeponides bradyi le Calvez, Neoconorbina terquemi (Rzehak), Rosalina bradyi Cushman, R. globularis d'Orbigny, Cibicides advenum (d'Orbigny), Lobatula lobatula (Walker ve Jacob), Cibicidina walli Bandy, Planorbulina mediterranensis d'Orbigny, Asterigerinata mamilla (Williamson), Astrononion stelligerum (d'Orbigny), Ammonia compacta Hofker, A. parkinsoniana (d'Orbigny), A. tepida Cushman, Challengerella bradyi Billman, Hottinger ve Oesterle, Cribroelphidium poeyanum (d'Orbigny), Porosononion subgranosum (Egger), Elphidium aculeatum (d'Orbigny), E. advenum (Cushman), E. complanatum (d'Orbigny), E. crispum (Linné), E. macellum (Fichtel ve Moll), E. punctatum (Terquem) gibi toplam 31 cins ve 50 türdür (Çizelge 
2). Foraminiferlerin cins ve tür tayinlerinde Avşar ve Meriç, 2001; Meriç ve Avşar, 2001; Meriç vd., 2002a ve b; 2003a ve b; 2004; 2009b, c ve d; 2010, 2011, 2012a ve b; 2014a ve b, 2016; Yokeş vd., 2014; Yümün vd., 2016'dan yararlanılmıştır.

Çalışma bölgesi için dikkati çeken durum, Ege Denizi’nde Kuşadası Körfezi, Doğanbey Burnu ve Karaburun Yarımadası KB'sinda bilinen ve var olduğu düşünülen sıcak su kaynakları çevresinde bol olarak bulunan Amphistegina lobifera bireylerine bu alanda hiç rastlanılmamış olmasıdır. Diğer önemli bir bulge Suneru da, Ege Denizi'nin Türkiye kıyılarındaki farklı noktalarda saptanan Peneroplis pertusus, P. planatus, Coscinospira hemprichii, Sorites orbiculus bireylerinin çalışılan örneklerde gözlenmemiş olmasıdır. Bu özelliklerin dışında çalışma alanı için baskın cins ve türlerin Rosalina bradyi, Ammonia compacta, A. parkinsonana ve Elphidium crispum olduğu belirlenmiştir. İzmit Körfezi Geç Holosen çökellerinde bulunmuş olan (Meriç ve Suner, 1995) Cibicidina walli Ege Denizi'nde ilk kez ve çok az sayıda bu çalışmada gözlenmiştir.

\section{Ostrakod Topluluğu}

Örnekler ostrakod çeşitliliği açısından çok fazla zengin değildir. İncelenen 13 örnekte de ostrakod bulunmuş olup, cins ve tür açısından 1, 4, 6, 13, 14 no'lu örnekler fakir ve 7, 8, 9, 10, 11 no'lu örnekler ise foraminifer topluluğunda gözlendiği gibi oldukça zengindir (Çizelge 3).

Aliağa dip sediment örneklerinde ostrakodlardan 19 cins ve 28 tür bulunmuştur. Cins ve tür tayinlerinde ise Van Morkhoven (1963), Hartmann ve Puri (1974), Bonaduce vd. (1975), Breman (1975), Yassini (1979), Guillaume vd. (1985), Athersuch vd. (1989), Zangger ve Malz (1989), Mostafawi ve Matzke-Karasz (2006), Joachim ve Langer (2008) ile "MarBEF Data System" den (http://www.marbef.org/data/) gibi kaynaklardan yararlanılmıştır. Bulunan ostrakodlar Akdeniz ve Ege Denizi'nde bilinmekte olup, Cytheretta judaea, Hiltermannicythere turbida, Cushmanidea turbida, Loxoconcha bairdi, Semicytherura inversa, Xestoleberis communis, Xestoleberis dispar türleri çalışılan örneklerde yaygindir.

\section{Mollusk Topluluğu}

Bivalv ve gastropod olarak bu alanda tipik Ege Denizi mollusk faunası baskındır (Öztürk vd., 2014; Yümün vd., 2016). İncelenen 13 örnekte de gastropod ve bivalv'lere rastlanılmıştır (Çizelge 4). Gastropodlardan Gibbula albida (Gmelin), Tricolia pullus (Linné), Bittium latreillii (Payraudeau), B. submamillatum (de Rayneval ve Ponzi), Turritella communis Risso, Marshallora adversa (Montagu), Pusillina inconspicua (Alder), Alvania geryonia (Nardo), Odostomella doliolum (Philippi), Ondina modiola (Monterosato) gibi 9 cins ve 10 tür, bivalvlerden ise Nucula hanleyi Winckworth, Lembulus pella (Linné), Striarca lactea (Linné), Flexopecten hyalinus (Poli), Mimachlamys varia (Linné), Ctena decussata (O.G. Costa), Lucinella divaricata (Linné), Cardites antiquatus (Linné), Acanthocardia tuberculata (Linné), Parvicardium scriptum (Bucquoy, Dautzenberg ve Dollfus), Papillicardium papillosum (Poli), Timoclea ovata (Pennant), Gouldia minima (Montagu), Myrtea spinifera (Montagu) olarak 14 cins ve 14 tür bulunmuştur. (Cossignani vd., 2011; Scaperrotta vd., 2009-2015).

Örnekler arasında içerdikleri cins ve tür sayısına göre farklılık gözlenmiştir. 10 ve 11 no'lu örnekte her iki gruptan birer tür, 6, 9 ve 12 no'lu örneklerde 7 tür ve 3 ile 5 no'lu örneklerde ise 8 tür belirlenmiştir (Çizelge 4). 
Çizelge 2. Bentik foraminifer cins ve türlerinin örneklere göre dağılımı.

Table 2. According to the samples, the distribution of benthic foraminifer genera and species.

\begin{tabular}{|c|c|c|c|c|c|c|c|c|c|c|c|c|c|}
\hline \multirow{2}{*}{ FORAMINIIFERA } & \multicolumn{13}{|c|}{ İSTASYON NO. } \\
\hline & A1 & A2 & A3 & A4 & A5 & A6 & A7 & A8 & A9 & A10 & A11 & A12 & A13 \\
\hline Vertebralina striata & & & & & & & + & & & & & & \\
\hline Nubecularia lucifuga & & & & & & & + & & & + & & & \\
\hline Adelosina cliarensis & & + & + & + & + & + & + & + & & & & + & + \\
\hline Adelosina duthiersi & & & + & + & & & & + & + & & + & + & \\
\hline Adelosina mediterranensis & + & & + & & + & + & + & + & + & + & & + & + \\
\hline Adelosina partschi & & + & & + & & & & & & & & & + \\
\hline Spiroloculina angulata & & & & & & + & & & & & & & \\
\hline Spiroloculina angulosa & & & & & & + & & & & & & & \\
\hline Spiroloculina excavata & & & & & & & + & & + & & & & + \\
\hline Spiroloculina ornata & & + & & + & & + & + & + & + & + & & & \\
\hline Siphonaperta aspera & & & & + & & + & & & & & + & & \\
\hline Cycloforina contorta & + & + & + & + & + & & + & + & + & + & + & + & + \\
\hline Lachlanella bicornis & & & & & & + & & & & & & & + \\
\hline Massilina secans & & & & & & & + & & & & & & \\
\hline Quinqueloculina berthelotiana & & & & & & & & + & & & & + & \\
\hline Quinqueloculina jugosa & & & + & + & & & & & & & & & \\
\hline Quinqueloculina lamarckiana & & & + & & + & + & & 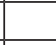 & + & & & & \\
\hline Quinqueloculina seminula & + & + & & & + & + & + & & & & + & + & \\
\hline Miliolinella labiosa & & & & & & & + & & & & & & \\
\hline Miliolinella subrotunda & & & & & + & & & + & & & + & + & + \\
\hline Pseudotriloculina laevigata & & & & & & & + & + & & & & & + \\
\hline Pseudotriloculina rotunda & & & & & & & & + & & + & & & \\
\hline Pyrgo elongata & & & & & + & & + & & & & & & \\
\hline Triloculina marioni & + & & + & & + & & + & + & + & + & + & + & + \\
\hline Triloculina tricarinata & & & & & & & + & & & & & & \\
\hline Welmanellinella striata & & + & & & & & & & & & & & \\
\hline Sigmoilinita costata & & + & + & & + & & + & + & + & & & & + \\
\hline Reussella spinulosa & & & & & & & + & & + & + & & + & + \\
\hline Valvulineria bradyana & & & & & & & & & & & & + & \\
\hline Neoeponides bradyi & + & & + & + & + & + & & & + & & & & + \\
\hline Neoconorbina terquemi & & & + & + & & + & + & + & & + & + & + & + \\
\hline Rosalina bradyi & + & + & + & + & + & + & + & + & + & + & + & + & \\
\hline Rosalina globularis & & & & & & & + & + & + & & & & \\
\hline Cibicides advenum & & & & & & & & & & + & & & + \\
\hline Lobatula lobatula & + & + & + & + & + & + & + & + & & + & + & + & + \\
\hline Cibicidina walli & & & & & & + & & & & & & + & + \\
\hline Planorbulina mediterranensis & & & & & & & + & & & & & & \\
\hline Cibicidella variabilis & & & & & & & + & & & & & & \\
\hline Asterigerinata mamilla & + & + & & + & + & + & & + & + & + & + & + & + \\
\hline Astrononion stelligerum & & & & & & & & & & + & & & \\
\hline Ammonia compacta & + & + & + & + & + & & + & + & + & + & + & + & + \\
\hline Ammonia parkinsoniana & & + & & & + & + & + & + & + & + & + & & + \\
\hline Ammonia tepida & & & & & & & & & & + & + & & + \\
\hline Challengerella bradyi & + & & & + & & + & & & & & & + & \\
\hline Cribroelphidium poeyanum & & & & & & & & + & + & & + & & + \\
\hline Porosononion subgranosum & & & & & & & & + & + & & + & + & + \\
\hline Elphidium aculeatum & & & & & + & & + & & & + & + & + & \\
\hline Elphidium advenum & + & + & & + & & + & & + & & + & & + & \\
\hline Elphidium complanatum & + & & + & + & + & + & + & + & + & + & + & + & + \\
\hline Elphidium crispum & + & + & + & + & + & + & + & + & + & & + & + & + \\
\hline Elphidium macellum & + & & & & + & + & + & + & + & + & + & + & \\
\hline Elphidium punctatum & + & & & & & + & + & & + & & & & + \\
\hline
\end{tabular}


Çizelge 3. Ostrakod cins ve türlerinin örneklere göre dağılımı.

Table 3. According to the samples, the distribution of ostracod genera and species.

\begin{tabular}{|c|c|c|c|c|c|c|c|c|c|c|c|c|c|}
\hline \multirow[b]{2}{*}{ OSTRACODA } & \multicolumn{13}{|c|}{ İSTASYON NO. } \\
\hline & A1 & A2 & A3 & A4 & A5 & A6 & A7 & A8 & A9 & A10 & A11 & A12 & A13 \\
\hline Neonesidea mediterranea & & & & + & & & + & & & & & & \\
\hline Aurila convexa & + & & & & & & & & & & & + & + \\
\hline Jugosocythereis prava & & & & & & & + & & & + & & & \\
\hline Cyprideis torosa & & & + & & & + & & & & & & & \\
\hline Microcytherura sp. & & & & & & & & & & & & & + \\
\hline Callistocythere intricatoides & & & & & & & & & & & & + & + \\
\hline Callistocythere pallida & & & & & & & + & + & & & & & \\
\hline Callistocythere rastrifera & & & & + & & & & & & & & & \\
\hline Carinocythereis carinata & & & & & + & + & + & & + & & & & \\
\hline Costa batei & & & & & & & + & & & & & & \\
\hline Costa edwardsii & & & & & & & + & + & & & & & + \\
\hline Acanthocythereis hystrix & & & & & & & + & + & & + & & & \\
\hline Pterygocythereis jonesii & & & & & + & & + & & & & & & + \\
\hline Bosquetina carinella & & & & & + & & + & & + & & & & + \\
\hline Cytheretta judaea & & & + & + & & + & & & & & & + & + \\
\hline Hiltermannicythere turbida & & & + & + & + & + & & & & & & + & \\
\hline Hiltermannicythere rubra & + & & & + & & + & & & & & & & + \\
\hline Microceratina sp. & & & & & & + & + & + & & & & & \\
\hline Cushmanidea turbida & + & & + & + & + & + & & & & & & + & \\
\hline Loxoconcha bairdi & + & & + & + & + & + & + & + & + & + & & + & + \\
\hline Loxoconcha elliptica & & & & & & + & & & & & & & \\
\hline Paracytheridea depressa & & & & & & & & & + & & & & + \\
\hline Semicytherura incongruens & & & & & + & & & & & & & + & \\
\hline Semicytherura inversa & & + & + & + & + & & & & + & & & + & + \\
\hline Semicytherura paradoxa & & & & & & & + & & & & & & \\
\hline Xestoleberis communis & & & + & + & + & + & + & + & & + & + & + & + \\
\hline Xestoleberis depressa & & & & & & & & + & & + & & & + \\
\hline Xestoleberis dispar & + & & & + & + & + & & + & & & & + & + \\
\hline
\end{tabular}


Çizelge 4. Gastropod ile bivalv cins ve türlerinin örneklere göre dağılımı.

Table 4. According to the samples, the distribution of gastropod and bivalvia genera and species.

\begin{tabular}{|c|c|c|c|c|c|c|c|c|c|c|c|c|c|}
\hline MOLLUSKA & \multicolumn{13}{|c|}{ İSTASYON NO. } \\
\hline GASTROPODA & A1 & $\mathbf{A 2}$ & A3 & A4 & A5 & A6 & A7 & A8 & A9 & A10 & A11 & A12 & A13 \\
\hline Gibbula albida & & & & & & & & + & & & & & \\
\hline Tricolia pullus & & & + & & & & & & & & & + & \\
\hline Bittium latreillii & & + & & + & + & + & & + & + & & & + & + \\
\hline Bittium submammillatum & + & & + & + & + & & + & + & + & & & & + \\
\hline Turritella communis & & & & & + & & & & & & & & + \\
\hline Marshallora adversa & & & & & & + & & & & & & & \\
\hline Pusillina inconspicua & & & & & & & + & & & & & & \\
\hline Alvania geryonia & & & & & & & & & + & & & & \\
\hline Odostomella doliolum & & & & & & & & & & + & & & \\
\hline Ondina modiola & & & & & & & & & & & & + & \\
\hline \multicolumn{14}{|l|}{ BIVALVIA } \\
\hline Nucula hanleyi & & & & + & + & + & & & + & & & & + \\
\hline Lembulus pella & & & + & + & + & + & & & & & & & \\
\hline Striarca lactea & + & + & & & & + & & + & & & & & + \\
\hline Flexopecten hyalinus & & & & & & & + & & & & + & & \\
\hline Mimachlamys varia & & & + & & & & & & + & & & & \\
\hline Ctena decussata & & & + & & + & & & & & & & & \\
\hline Lucinella divaricata & & & & & & + & & & & & & & \\
\hline Cardites antiquatus & & & & & & & & & & & & + & \\
\hline Acanthocardia tuberculata & & & & & & & & & & & & + & + \\
\hline Parvicardium scriptum & & + & & & & & & & & & & & \\
\hline Papillicardium papillosum & & & & & & & + & & & & & + & \\
\hline Timoclea ovata & + & + & + & + & & + & & & + & & & & \\
\hline Gouldia minima & & & + & + & + & & & & & & & + & + \\
\hline Myrtea spinifera & & & + & & + & & & & + & & & & \\
\hline
\end{tabular}

\section{Jips Kristalleri}

Aliağa bölgesinde Ilıca Burnu ile Taşlı Burun arasında 11 nolu örnekte (K3849200, D2654430) $17 \mathrm{~m}$ su derinliğine sahip deniz tabanındaki tortullar içinden alınmış jipsler binoküler ve taramalı elektron mikroskop (SEM) ile incelenmiş ve fotoğraflanmıştır (Şekil 9). Jipsler 2 ile 3 mm arasında değişen boyutlarda sarımsı açık kahverengi doğal renkler sunmaktadır. Disk şekilli mikro jips kristallerin C-eksenleri (büyüme doğrultuları) basık kristal yüzeyine dik şekilde büyümüşlerdir. Kristallerin c-eksenleri ortamdaki yosunların büyüme doğrultusuna paralel ve uyumludur. Bazı jips kristallerin çekirdeklerinde çok az miktarda kalsit minerali tespit edilmiştir. Mikro disk şekilli jipslerin kristal yüzeyleri oldukça düzgün bu görüntüye sahip olup herhangi bir taşınma veya yeniden işlenme geçirmemişlerdir. $\mathrm{Bu}$ tür disk şekilli jipsler genel olarak $\mathrm{Abu}$ Dhabi'nin gelgit çamur düzlükleri gibi sabkha olarak adlandırılan alanlarda tortullar arasında oluşuk-içi (interstitial) olarak kapiler deniz suyundan kristalleşerek oluşmaktadır (Shearman, 1978). Karasal alanlarda Tuzgölü ve Acıgöl gibi 
göllerin sslak çamur düzlükleri içinde de benzer disk şekilli jips kristalleri gözlenebilmektedir (Gündoğan ve Helvac1, 1996). Bu tür jipsler aynı zamanda deniz suyundan tuz üretim alanlarında (tuzla) buharlaşmayla derişimin arttırıldığ 1 tortul çökeller içinde de gözlenebilir. İspanya'nın Alicante yakınlarındaki Santa Pola tuzlasında deniz suyu 150 g/l (\% 150 tuzluluk) derişime ulaştığı ortamlarda çamur tortullar içinde benzer diskoidal jipsler oluşmaktadır (Orti vd., 1984).

Aliağa bölgesinde Ilıca Burnu ile Taşlı Burun arasından denizin $17 \mathrm{~m}$ altındaki tortullar içinde oluşan mikro-disk şekilli jipsler yukarıda örnekleri verilen sabkha türü ortamlardan farkl1 bir kristalleşme ortamını işaret etmektedir. $\mathrm{Bu}$ tür diskoidal jips minerallerin Aliağa bölgesinde tuzluluğu \%o38,5-39,5 olan Ilıca Burnunda deniz suyunda doğal olarak kristalleşmesi mümkün değildir. Mevcut deniz suyu bileşimi Ca-sülfatça zengin hidrotermal sularla beslenmesi ve deniz tabanında göreceli olarak derişimin artması durumunda bu tür jipslerin tortullar içinde kristalleşmesi mümkün olabilir. Örneklerin alındığ1 bölgenin "Ilıca Burnu" adıyla anılması böyle bir olasılığın çok güçlü olduğuna işaret etmektedir. Türkiye'de deniz tabanlarında sıcak termal sulara bağlı olarak oluşmuş jips kristalleri önceki çalışmalarda İzmit Körfezi Hersek Burnu ile Kaba Burun arasında (Meriç ve Suner 1995) ve
Haliç-İstanbul Holosen tortullarında (Suner vd., 2012) tespit edilmiştir. Deniz tabanlarındaki bu tür jips oluşumların hidrotemal akışkanlarla ilişkisinin detaylı olarak ortaya konmasıyla gömülü fay hatları hakkında kılavuz veriler sağlanabilir.

\section{Sediment ve Su Örneklerinin Kimyasal Özelliklerinin Değerlendirilmesi}

ICP-MS ile yapılan sediment analizlerinde ağır metallerden $\mathrm{Zn}, \mathrm{Pb}, \mathrm{Cu}$ ve As dağılımında A11 de en yüksek değer bulunmuştur. Yüksek olan Ni sadece A1 de, Cu dağılımı A7, A9, A10 ve A11'de, $\mathrm{Cd}$ ise A2 ve A4 hariç tüm örneklerde yüksek, Co ise tüm örneklerde düşüktür. Eser elementlerden Sr ve $\mathrm{Ba}$ dağılımı yüksek belirlenmiştir. Diğer eser elementlerden Sc, Y, Th, As, Sr, Au dağılımı tüm öneklerde referans değerinden yüksektir. Cs dağglımı A7 ve A8'de, Eu A2'de yüksek bulunmuştur.

Mağarada bulunan kaynak suyu ve deniz yüzeyinden alınan örneklerde yapılan eser element analizlerinde $\mathrm{Ag}, \mathrm{Co}, \mathrm{Cu}, \mathrm{Mo}, \mathrm{Pb}, \mathrm{B}, \mathrm{Ba}$, $\mathrm{Be}, \mathrm{Li}, \mathrm{Se}, \mathrm{Sn}, \mathrm{Sr}$ ve Ti bulunmuştur (Çizelge 5). Her iki örnekte de As, Bi, Ni, Pb, Sb, V, Zn ve Sc ölçülememiştir. B ve Li değerleri birbirine yakın ve yüksektir. En yüksek değerler B ve Li deniz yüzeyinde, Sr ise kaynak suyunda ölçülmüsştür. 

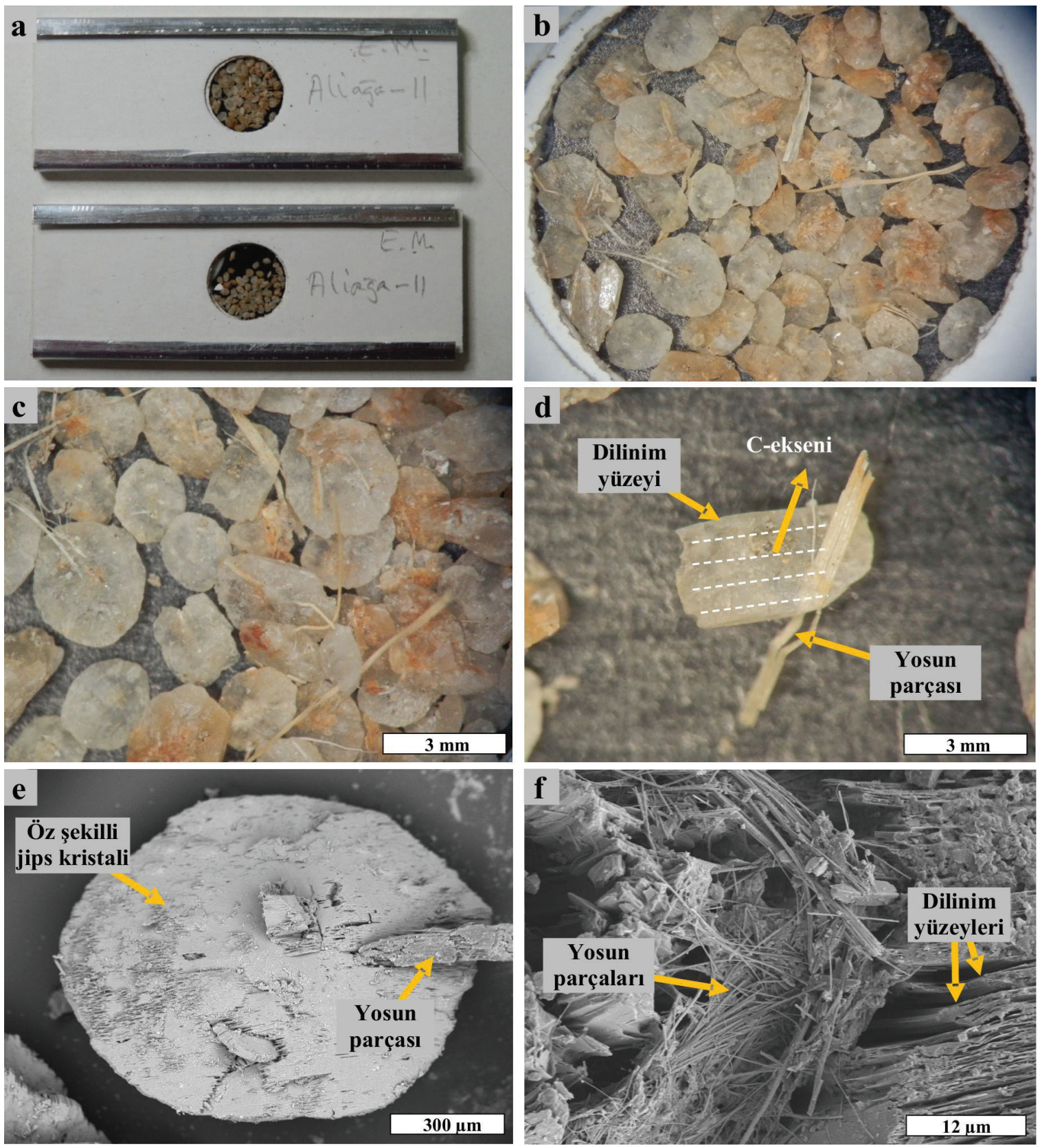

Şekil 9. Aliağa bölgesinde Ilıca Burnu ile Taşı Burun arasında alınan A11 no’lu örnekte gözlenen öz şekilli jips kristalleri: a, b ve c) Jips kristallerin binoküler mikroskop görüntüleri. d) Deniz tabanı tortulları içinde tortul-su ara yüzeyine yakın kristalleşmiş jips minerali içinde kapanlanmış yosun parçası. Jips kristalin c-ekseni yosunun büyüme doğrultuna paralel olarak gelişmiştir. e ve f) Yosun kapanımları içeren öz şekilli jips kristallerin taramalı elektron mikroksop (SEM) görüntüleri.

Figure 9. Euhedral discoidal gypsum crystals observed in A11 sample taken from marine sediments between Ilica Foreland and Taşlı Foreland in the Aliağa region. ( $a, b$ and c) Binocular microscope images of gypsum crystals. (d) Algae fragment trapped in gypsum mineral crystallized near the sediment-water interface within the marine sediments. C-axis of the gypsum crystal was developed parallel to the growth direction of the algae. (e and f) Scanning electron microscope (SEM) images of euhedral gypsum crystals containing algae inclusions. 
Çizelge 5. D1 (Deniz suyu) ve M1 (Mağara içinden çıkan su) sularının eser element analizleri.

Table 5. The trace element analyses of the waters collected from D1 (Marine water) and M1 (Spring water in the Cave).

\begin{tabular}{|c|c|c|}
\hline $\begin{array}{c}\text { Element } \\
\text { ppm }\end{array}$ & M1 & D1 \\
\hline $\mathrm{Ag}$ & 0,013 & 0,009 \\
\hline As & ND & ND \\
\hline $\mathbf{B i}$ & ND & ND \\
\hline Co & 0,005 & 0,005 \\
\hline $\mathrm{Cu}$ & 0,019 & 0,018 \\
\hline Mo & 0,002 & 0,001 \\
\hline $\mathrm{Ni}$ & ND & ND \\
\hline $\mathbf{P b}$ & 0,004 & ND \\
\hline Sb & ND & ND \\
\hline $\mathbf{V}$ & ND & ND \\
\hline $\mathbf{Z n}$ & ND & ND \\
\hline B & 12,248 & 12,670 \\
\hline $\mathrm{Ba}$ & 0,059 & 0,068 \\
\hline $\mathrm{Be}$ & 0,001 & 0,001 \\
\hline $\mathrm{Cr}$ & 0,000 & 0,000 \\
\hline $\mathbf{L i}$ & 9,111 & 9,569 \\
\hline $\mathrm{Se}$ & 0,028 & 0,050 \\
\hline Sn & 0,028 & 0,036 \\
\hline $\mathrm{Sr}$ & 16,372 & 13,117 \\
\hline $\mathbf{T i}$ & 0,003 & 0,001 \\
\hline Sc & ND & ND \\
\hline
\end{tabular}

Deniz ve Kaynak Sularının Toplam Alfa ve Beta Özelliklerinin Değerlendirilmesi

D1 (deniz suyu) ve M1 (mağarada çıkan kaynak suyu) sularında toplam alfa ve beta $(\mathrm{Bq} / \mathrm{l})$ okumaları gerçekleştirilmiştir. Her iki örnekte de bu değerler referans değerden yüksek ölçülmekle birlikte D1'de toplam alfa ve beta daha yüksektir. Toplam çözünmüş madde miktarı (TDS) (g/l) ise M1'de yüksektir (Çizelge 6).
Çizelge 6. D1 (Deniz suyu) ve M1 (Mağara içinden çıkan su) sularının toplam alfa ve beta değerleri.

Table 6. The total alpha and beta values of the waters collected from D1 (Marine water) and M1 (Spring water in the Cave).

\begin{tabular}{|l|l|l|}
\hline Örnek ID & D-1 & M-1 \\
\hline Tarih & 08.03 .2018 & 08.03 .2018 \\
\hline Örnek miktarı $(\mathrm{l})$ & $1,5 \mathrm{~L}$ & $1,5 \mathrm{~L}$ \\
\hline Toplam Alfa $(\mathrm{Bq} / \mathrm{l})$ & 3,95 & 3,04 \\
\hline \pm & 0,26 & 0,20 \\
\hline Toplam Beta $(\mathrm{Bq} / \mathrm{l})$ & 14,21 & 14,00 \\
\hline \pm & 2,96 & 2,94 \\
\hline TDS $(\mathrm{g} / \mathrm{l})$ & 24,4 & 25,7 \\
\hline
\end{tabular}

\section{TARTIŞMA VE SONUÇLAR}

Elde edilen bulgular, daha önce çalışılan Kuşadası, Doğanbey, Karaburun Yarımadası kuzeybatısı gibi alanlardaki sonuçlarla karşılaştırıldığında anlamlı bir farklılık ortaya çıkmaktadır (Meriç vd., 2012b; Yokeş vd., 2014). Ad1 geçen üç bölgede gözlenmiş olan Peneroplis pertusus, P. planatus, Coscinospira hemprichii, Sorites orbiculus ve Amphistegina lobifera bireylerine çalışmamızda incelenen örneklerde rastlanılmamıştır. Bu özellik, söz konusu alanda ki genel özellikler nedeniyle diğer bölgeler ile farklılık içermektedir. Halbuki, Ege Denizi'nin Türkiye kıyılarında, daha kuzey noktalarda, hatta Çanakkale Boğazı ile Marmara Denizi'nde adı geçen foraminifer cins ve türlerine zaman zaman rastlanılmıştır (Sakınç, 2008; Meriç vd., 2009c; 2012c; Yümün, 2017). Bu durum, denizlerdeki bazı noktalarda çok farklı ekolojik koşulların varlığına işaret etmekte olup, örnek olarak Çeşme Ilıca Koyu gösterilebilir (Meriç vd., 2012a). Burada $28.4^{\circ} \mathrm{C}$ sıcak su çıktısının varlığına karşın Amphistegina lobifera dışında yukarıda adı geçen diğer bentik foraminiferler de bulunmuştur. Ayrıca, Kuşadası Körfezi, Ilıca Koyu ve Karaburun Yarımadası KB'da oldukça fazla sayıda denilebilecek güney Pasifik ve Kızıldeniz kökenli Euthomonacha polita ile Coscinospira acicularis bireylerine rastlanılmıştır. Kuşadası 
Körfezi sıcak su kaynağı çevresindeki sıcaklık $17.5^{\circ} \mathrm{C}$, Doğanbey'de $19.0-20.0^{\circ} \mathrm{C}$, Karaburun Yarımadası kuzeybatısında var olduğu düşünülen sıcak su çıktısı yakınlarında $16.8-17.0^{\circ} \mathrm{C}^{\prime}$ dir. Aliağa Ilıca Burnu'ndaki $51^{\circ} \mathrm{C}$ ve $40^{\circ} \mathrm{C}$ sicaklık sunan 2 sicak su kaynağ 1 çevresinde ise adı geçen 5 bentik foraminifer ile göçmen foraminiferler saptanmamıştır. Ayrıca, eskibirkaynağın göstergesi olarak saptanan jipslerin bulunduğu A11 no'lu örnekte ostrakodlardan bir tür ve bivalvlerden bir tür bulunmuştur. Bölgede gözlenen bu durum ile Midilli adası doğu kesiminde bulunan deniz içi sıcak su kaynakları benzer özelliklertedir. Midilli Adası doğusunda Midilli (Mytilene) yerleşim merkezi kuzeybatısında bulunan Pirgi Termis kuzeyinde deniz içindeki sıcak su kaynağ1 çevresinde foraminifer topluluğu gözlenmiştir (Meriç vd., 2002a). Adadaki kaplıcaların sıcaklığ $39.7-46.9^{\circ} \mathrm{C}$ ve tuzlu su özelliğini taşımaktadır. Bazı kaplıcalarda ise su sıcaklığ $169.0^{\circ} \mathrm{C}$ ye kadar ulaşmakta olup bu bölgede de Amphistegina lobifera bulunmamıştır.

Daha önceki yıllarda da, Ege Denizi Santorini Adası çevresinde yer alan sıcak su kaynakları yakın çevresinden güncel sediment örneği elde edilmiş ve yapılan inceleme sonucunda hiçbir foraminifer ve diğer topluluklara ait herhangi bir bulguya rastlanılmamıştır. Bilindiği gibi ostrakod, mollusk, foraminifer cins ve türlerinin yaşam koşulları için belirli bir sıcaklık değeri olması gerekmektedir. Ilıca Burnu kaynaklarındaki sıcaklık değerinin yaşam koşulları için çok yüksek olduğu, $\mathrm{Zn}, \mathrm{Pb}$, $\mathrm{Cu}$ ve As gibi eser element değerlerinin yüksekliği özellikle Amphistegina lobifera, Peneroplis pertusus, P. planatus, Coscinospira hemprichii, Sorites orbiculus ve Amphistegina lobifera topluluğunun olumsuz olarak etkilendiğini göstermektedir. Önümüzdeki y1llarda genç araştırıcıların, Peneroplis pertusus, P. planatus, Coscinospira hemprichii, Sorites orbiculus ve Amphistegina lobifera gibi bentik foraminiferlerin yaşadıkları ortamlardan alınan sediment örnekleri üzerinde yeni araştırma yöntemleri kullanarak çevresel fiziksel ve kimyasal şartları ayrıntılı bir şekilde incelemeleri ve bu konu üzerinde yeni bulgular ortaya koymaları önerilmektedir.

\section{EXTENDED SUMMARY}

In recent years, the researches on morphological abnormalities on foraminifera tests have been increased due to different ecological conditions in the Mediterranean and Aegean Sea. One of the factors that change the ecological conditions is thermal waters those have input into sea water. This study was carried out around Aliağa Bay (İzmir). Two thermal springs, with $40^{\circ} \mathrm{C}$ ve $51^{\circ}$ $C$ temperatures, are closely located on the coast of Ilica Cape, northwest of Aliağa and northwest of Karaă̆aç Cove. Aliağa Bay is located between the north İmir Gulf in the west of Turkey (between Taşlı Cape-Kabakhisarl Cape). Maximum depth is $33 \mathrm{~m}$, here is located a narrow channel between the Tassl l Cape and the Kabakhisari Cape. The average slope of Doğanbey Bay varies between 2-4\% (Eryllmaz vd. 2017). The area between Ilica Cape-Aliağa Bay - Kızll Cape and Tavşan Island is generally shallow marine environment, depth ranges from $30.00-50.00 \mathrm{~m}$. In the investigated area, the temperature of the surface waters is changing depending on the weather temperature. The highest salinity on the surface water is 39.40 $\%$ (in the summer season). Salinity difference between surface and the lower layers at the sea water is very close to each other in all seasons in the region. At $20.00 \mathrm{~m}$ depth, it is the lowest at \%o 38.58 (in the winter season) and the highest at \%o 39.25 (in the summer). In this region, grain size generally is transitional from coarse to fine grain. The sediments consist of five type sedimentary material such as rock fragments, gravel, sand, silt and clay.

The aim of this study a) to reveal the effects of the thermal spring on the benthic foraminifer, ostracod and mollusc assemblages in 13 sediment samples which have been collected from different 
stations and depths between Ilica and Taşl Cape. b) to figure out the reasons of the observed differences in foraminiferal assemblages around the thermal springs known or suggested to be present on the Turkish Aegean coasts.

Typical Aegean Sea foraminifer fauna has been found in the study area, represented with 32 genera and 52 species. Besides, colored foraminifer tests, which is a common phenomenon on the Aegean coast, were observed only in few cases, whereas, morphological abnormalities were abundant. No alien foraminifer species was recorded. The absence of typical species abundantly observed on the Turkish Aegean coasts, such as Amphistegina lobifera, Peneroplis pertusus, P. planatus, Amphisorus hemprichii and Sorites orbiculus constituted an important peculiarity of the region. Beside these foraminifers, poor ostracod and mollusc assemblages, typical of Aegean Sea fauna, were observed in the sediment samples.

Another characteristic is presence of many singular gypsum crystals found in Sample All. Micro-disc shaped gypsums formed in sediments below $17 \mathrm{~m}$ of the sea water between Ilica Cape and Taşl Cape in the Aliağa region indicate a different crystallization environment from the Sabkha type environments. These gypsums point out the presence of another thermal spring which has disappeared on a local fault line.

Sediment analysis performed by ICP-MS showed that highest values for the heavy metals zinc ( $\mathrm{Zn})$, lead (Pb), copper (Cu) and arsenic (As) were measured in A11. On the other hand, high values of nickel (Ni) observed only in $\mathrm{Al}$ and $\mathrm{Cu}$ in A7, A9, A10 and A11. Cd values were high in all the samples, except $A 2$ and $A 4$.

Cobalt (Co) values were found as low in all samples analyzed. The distribution of the trace elements strontium (Sr) and barium (Ba) were observed high. The values of the other trace elements, scandium (Sc), yttrium (Y), thorium
(Th), As, Sr and gold (Au) were higher than the reference value in all samples. High levels of Cs were found in $A 7$ and $A 8$, of europium (Eu) in A2.

When the meiobenthic assemblages are correlated with acording to sampling stations, very rich fauna were found at the sample A7, A10, A13 for benthic foraminifera, at the sample A7, A13 for ostracods and at the sample A3, A5 for molluscs.

\section{ORCID}

Engin Meriç D https://orcid.org/0000-0002-5975-3678 Atike Nazik (D) https://orcid.org/0000-0001-7996-7430 M. Baki Yokeş (D https://orcid.org/0000-0002-9440-4561 Ipek F. Barut D https://orcid.org/0000-0002-4255-0268 Mustafa Kumral D https://orcid.org/0000-0001-7827-8721 Mustafa Eryılmaz D https://orcid.org/0000-0002-3342-768X Fulya Yücesoy-Eryılmaz D https://orcid.org/0000-0003-3714-6903 İbrahim Gündoğan D https://orcid.org/0000-0002-2148-3377 Bora Sonuvar D https://orcid.org/0000-0001-9894-3709 Feyza Dinçer D https://orcid.org/0000-0001-6105-4369

\section{DEĞIINILLEN BELGELER}

Athersuch, J., Horne, D.J. ve Whittaker, J.E. 1989. Marine and brackish water ostracods. Synopses of the British Fauna (New Series), E.J.Brill., 43, $1-343$.

Avşar, N. ve Meriç, E., 2001, Çeşme-Ilıca Koyu (İzmir) bölgesi güncel bentik foraminiferlerinin sistematik dağ 1 lımı. H. Ü. Yerbilimleri, 24, 13-22, Ankara.

Babin, C. 1980, Elements of Palaeontology. John Wiley and Sons. Chichester. 446s. ISBN 0471275778 (56 Bab).

Bignot, G., 1985, Elements of micropaleontology. London: Graham and Trotman Ltd., 217s.

Bonaduce, G., Ciampo, G. ve Masoli, M. 1975. Distribution of ostracoda in the Adriatic Sea. Pubblicazioni della Stazione Zoologica di Napoli 40 (Suppl.), 1-304. 
Breman, E. 1975. The Distribution of Ostracodes in the Bottom Sediments Of The Adriatic Sea. Vrije Universiteit te Amsterdam, Krips Repro, Meppel, 1-165.

Cossignani T., Ardovani R., Micali P., Tisselli M., Cossignani V. ve Cecalupo A., 2011, Malacologia Mediterranea: Atlante delle Conchiglie del Mediterraneo. L'Informatore Piceno, Cupra Marittima, Italy, 536pp.

Eryılmaz, M. ve Yücesoy-Eryılmaz F. 2001, Ege Denizi'nin sualtı morfolojisi ve Anadolu'nun Doğu Ege Denizi'ndeki doğal uzantısı. Ç.Ü. Yerbilimleri (Geosound), 39, 117-132, ISSN 1019-1003, Adana.

Eryılmaz, M., ve Yücesoy Eryılmaz, F., 2012, Dikili Kanalı'nın (Kd Ege Denizi) Oşinografisi. SBT 2012, Sualtı Bilim ve Teknolojileri Toplantıları 17-18 Kasım 2012 Bildiriler kitab1 152 s., 127135, İstanbul.

Eryılmaz, M., Kırca, Z. ve Aydın, Ş., 1999, Türkiye, Ege Denizi, yüzey sediment dağılım haritası (tane büyüklüğüne göre), Ölçek, 1: 1.102.000, Dz.K.K. Sey. Hid. ve Oşi. Dairesi Başkanlığı, Mayıs 2001, İstanbul.

Eryılmaz, M., Yücesoy Eryılmaz, F. ve Eryılmaz, U., 2017. Aliağa Koyu'nun (doğu Ege Denizi) oşinografisi ve güncel çökel dağılımı. 70. Türkiye Jeoloji Kurultay1, Ankara, 10-14 Nisan 2017, 106107.

Filiz, Ş., Tarcan, G., Gemici, Ü., 1997, Aliağa (İzmir) jeotermal alanındaki sahil ılıcalarının hidrojeokimyasal incelemesi. TPJD Bülteni, 9 (1), 45-58.

Folk, L. R., 1974, Petrology of sedtimentary rock. Hemphill Publ. Co. Texas, 182 p.

Guillaume, M.C., Peypouquet, J.P ve Tetart, J. 1985. Quaternaire et actuel. Atlas des Ostracodes de France. H.J. Oertli (Ed.). Bulletin Centres Rechearche Exploration Proceeding ElfAquitaine. Mémoire 9, 337-377.

Gündoğan, İ., and Helvac1 C., (1996). Geology, mineralogy, geochemistry and economic potantial of the Bolluk Lake and adjacent area CihanbeyliKonya. Tr. J. of Earth Sciences, 5/2, 91-104.

Hartmann, G. ve Puri, S.H. 1974. Summary of neontological and paleontotogical classification of ostracoda, Mitteilungen aus dem Zoologischen
Staatsinstitut und Zoologischem Museum in Hamburg, Band, 70, 7-73.

Joachim, C. ve Langer, M.R. 2008. The 80 most common Ostracods from the Bay of Fetovaia Elba Island (Mediterranean Sea). Universität Bonn, $29 \mathrm{~s}$.

“MarBEF Data System” (http://www.marbef.org/data/) http://www.marbef.org/data/

Meriç, E., 1986. Deniz dibi termal kaynakların canlı yaşamına etkisi hakkında güncel bir örnek (IlıcaÇeşme İzmir). Türkiye Jeoloji Kurumu Bülteni, 29 (2), 17-21.

Meriç, E. ve Suner, F., 1995. İzmit Körfezi (Hersek Burnu-Kaba Burun) Kuvaterner istifinde gözlenen termal veriler (Ed. E. Meriç), İzmit Körfezi Kuvaterner İstifi, 81-90, İstanbul.

Meriç, E. ve Avşar, N., 2001. Benthic foraminiferal fauna of Gökçeada Island (Northern Aegean Sea) and its local variations. Acta Adriatica, 42 (1), $125-150$.

Meriç, E., Avşar, N. ve Bergin, F., 2002a. Midilli Adası (Yunanistan-Kuzeydoğu Ege Denizi) bentik foraminifer faunası ve bu toplulukta gözlenen yerel değişimler. Ç.Ü. Yerbilimleri (Geosound), 40-41, 177-193.

Meriç, E., Avşar, N. ve Nazik, A., 2002b. Bozcaada (Kuzey Ege Denizi) bentik foraminifer ve ostrakod faunası ile bu toplulukta gözlenen yerel değişimler. Ç.Ü. Yerbilimleri (Geosound),40-41, 97-119.

Meriç, E., Avşar, N., Bergin, F. ve Barut, İ.F., 2003a. Edremit Körfezi (Kuzey Ege Denizi, Türkiye) bentik foraminifer topluluğu ile ekolojik koşulların incelenmesi. Ç.Ü. Yerbilimleri (Geosound), 43, 169-182.

Meriç, E., Avşar, N., Bergin, F. ve Barut, İ.F., 2003 b. A note on three abnormal samples of benthic foraminifers from the Dikili Bay (Turkey) in northeastern Aegean Sea: Peneroplis planatus (Fichtel ve Moll), Rosalina sp. ve Elphidium crispum (Linné). Bulletin of the Mineral Research and Exploration, 127, 1-14.

Meriç, E., Avşar, N. ve Bergin, F., 2004. Benthic foraminifera of Eastern Aegean Sea (Turkey) Systematics and Autoecology. Turkish Marine Research Foundation and Chamber Of Geological 
Engineers of Turkey, Publication No: 18, İstanbul, $306 \mathrm{~s}$.

Meriç, E., Avşar, N., Barut, İ.F., Yokeş, M.B. ve Dinçer, F., 2009a. Doğu Ege denizi kıy alanlarındaki termal Mineralli su kaynaklarının bentik foraminifer topluluklarına etkisi. İstanbul Yerbilimleri Dergisi 22 (2), 163-174.

Meriç, E., Avşar, N., Mekik, F., Yokeş, B., Barut, İ.F., Dora, Ö., Suner, F., Yücesoy-Ery1lmaz, F., Eryılmaz, M., Dinçer, F. ve Kam, E., 2009b. Alibey ve Maden Adaları (Ayvalık-Balıkesir) Çevresi Genç Çökellerinde Gözlenen Bentik Foraminifer Kavkılarındaki Anormal Oluşumlar ve Nedenleri. Türkiye Jeoloji Bülteni, 52(1), 31-84.

Meriç, E., Avşar, N., Barut, İ.F., Yokeş, M.B., Taş, S., Eryılmaz, M., Dinçer, F., Bircan, C., 2009c. Kuşadası (Aydın) Deniz Dibi Mineralli Su Kaynağı Çevresi Bentik Foraminifer Topluluğu Hakkında Görüs ve Yorumlar. 13. Sualtı Bilim ve Teknolojisi Toplantıs1 (SBT 2009) 7-8 Kasım 2009, Lefkoşa/KKTC, Bildiriler Kitabı, 80-92.

Meriç, E., Avsar, N., Barut, İ. F., Yokeş, M.B., Taş S., Eryilmaz, M., Dinçer, F., Bircan., C. 2009c. Opinion and comments on the benthic foraminiferal assemblages observed around the mineral submarine springs in Kuşadası (Aydın). Earth System Evolution and the Mediterrenean Area From 23 MA To The Present, Abst. Book, pp.222-223, Vol 45 n. 1/4, Italy 2009.

Meriç, E., Avşar, N., Nazik, A., Yokeş, B., Ergin, M., Eryılmaz, M., Yücesoy-Eryılmaz, F., Gökaşan, E., Suner, F., Tur, H., Aydın, Ş., Dinçer, F., 2009d. Çanakkale Boğazı'nın güncel bentik foraminifer, ostrakod ve mollusk topluluğunu denetleyen faktörler ile çökel dağılımının jeokimyası. T. J. Bült., 52 (2), 155-215, Ankara.

Meriç, E., Yokeş, M.B., Avşar, N. ve Bircan, C., 2010. An oasis for alien benthic foraminifera in the Aegean Sea. Aquatic Invasions, 5 (2), 191-195.

Meriç, E., Yokeş, B., Avşar, N., 2011. A new guest in Ilıca Bay (Çeşme-İzmir-Turkey); Coscinospira acicularis. Journal of Marine Biological Association of the United Kingdom, 4, e94, 1-5.

Meriç, E., Avşar, N., Nazik, A., Yokeş, M., Barut, İ. F., Eryılmaz, M., Kam, E., Taşkın, H., Başsarı, A., Dinçer, F., Bircan, C., Kaygun, A., 2012a, Ilıca Koyu (Çeşme-İzmir) bentik foraminifer-ostrakod toplulukları ile Pasifik Okyanusu ve Kızıldeniz kökenli göçmen foraminiferler ve anormal bireyler. M.T.A. Dergisi, 145, 62-78, Ankara.

Meriç, E., Avşar, N., Nazik, A., Yokeş, Dora, Ö., Barut, İ. F., Eryılmaz, M., Dinçer, F., Kam, E., Aksu, A., Taşkın, H., Başsarı, A., Bircan, C. ve Kaygun, A., 2012b. Karaburun Yarımadası kuzey kıyılarının oşinografik özelliklerinin bentik foraminifer ve ostrakod toplulukları üzerindeki etkileri. Maden Tetkik ve Arama Dergisi, 145, 22-47.

Meriç, E., Avşar, N., Nazik, A., Koçak, F., YücesoyEryılymaz, F., Eryılmaz, M., Barut, İ. F., Yokeş, M. B., Dinçer, F., Esenli, İ. F., Esenli, V., Özdemir, Z., Türker, A. ve Aydın, Ş., 2012c. Edremit Körfezi (Balıkesir) kıyı alanlarında oşinografik özelliklerin bentik foraminifer, ostrakod ve bryozoon toplulukları üzerindeki etkileri ile ilgili yeni veriler. Türkiye Petrol Jeologları Derneği Bülteni, 24 (2), 31-77.

Meriç, E., Öner , E., Avşar, N., Nazik, A., KapanYeşilyurt, S., Göksu, Y., Kaya-Keleş, Ş., Yokeş, B., Kam, E., Candan, O. ve Dinçer, F., 2014a. Gökçeada kuzeydoğusundaki Saklı koy'da paleontolojik verilere dayalı yeni bir bulgu: Büyük Dere Koyu. T.P.J.D. Bülteni, 26 (1), 67-97.

Meriç, E., Avşar, N., Yokeş, M. B. ve Dinçer, F., 2014b. Atlas of recent benthic foraminifera from Turkey. Micropaleontology, 60 (3-4), 211-398.

Meriç, E.,Yokeş, B., Avşar, N. ve Dinçer, F., 2016. New observations of alien foraminifera on the Turkish coasts of the Aegean Sea (20122015), International Journal of Environment and Geoinformatics, 3 (1), 44-47.

Mostafawi, N. ve Matzke-Karasz, R. 2006. Pliocene Ostracoda of Cephalonia, Greece. The Unrevised species of Uliczny (1969). Revista Española de Micropaleontología 38, 11-48.

Orti, F., Pueyo, J.J., Cussey, D.G. and Dulau, N., 1984. Evaporitic sedimentation in the coastal salinas of Santa Pola (Alicante, Spain). Revista D'investigacions Geologiques, Diputacion Provincial, Universidad de Barcelona, 38/39, 169220.

Öztürk B., Doğan A., Bitlis-Bakır B. ve Salman A., 2014. Marine molluses of the Turkish coasts: an updated checklist. Turkish Journal of Zoology. 38, 832-879. 
Sakınç, M., 2008, Marmara Denizi Bentik Foraminiferleri: Sistematik ve Otoekoloji. Istanbul Teknik Üniversitesi Rektörlüğü, İstanbul, 1638, 134s.

Scaperrotta, M., Bartolini, S. ve Bogi, C., 2009-2015, Accrescimenti - Stadi di accrescimento dei Molluschi marini del Mediterraneo - Stages of growth of marine molluscs of the Mediterranean Sea, I-VI.

Shearman, D.J., 1978. Evaporites of coastal sabkhas. In: Marine Evaporites (Ed.. by W.E. Dean and B.C. Schreiber). SEPM Short Cource No:4, 6-42.

Suner, F., Meriç, E., Avşar, N., ve Önal, B.Ç., 2012. Haliç (İstanbul-KB Türkiye) Holosen çökellerinde bireysel jips oluşumu ile bentik foraminifer ve ostrakod topluluğu ilişkisi. TPJD Bülteni, 24/1, 49-57.

Van Morkhoven, F.P.C.M. 1963. Post - Palaeozoic Ostracoda. Their Morphology, Taxonomy, and Economic Use, Vol. 2 Generic Descriptions, Amsterdam, London, New York, Elsevier Publishing Company, 478s.

Wentworth, C. K., 1922. A scale of grade and class terms for clastic sediments, Journal Geology, 30 377-392.

Yassini, I. 1979. The littoral system ostracodes from the bay of Bou-İsmail, Algiers, Algeria, National Iranian Oil Company. Revista Espanola de Micropaleontologia 11 (3), 353-416.

Yokeş, M. B., Meriç, E., Avşar, N., Barut, I., Taş, S., Eryılmaz, M., Dinçer, F. ve Bircan, C., 2014. Opinions and comments on the benthic foraminiferal assemblage observed around the mineral submarine spring in Kuşadası (Aydın, Turkey). Marine Biodiversity Record, 7, e103, 1-17.
Yücesoy-Eryılmaz, F., Eryılmaz, M., Özdemir, Z., Esenli, F., Aydın, Ş. ve Türker, A., 2002. Sedimentology and geochemistry of the recent sediments in the Edremit Gulf and Dikili Canal. Second International Conference, Oceanography of the Eastern Mediterranean and Black Sea, Similarites and differences of two Interconnected Basins 13-14 October. 2002, Ankara, 386s.

Yücesoy-Eryılmaz, F., Eryılmaz, M., Esenli, V. ve Özdemir, Z., 2004. Edremit Körfezi-Dikili Kanalı güncel çökellerinin mineralojisi ve ağır metal dağılımı. Kıyı ve Deniz Jeolojisi Sempozyumu (13-15 Eylül, 2004) Bildiri Özleri Kitabı, Yıldız Teknik Üniversitesi, İstanbul, 13-14.

Yücesoy-Eryılmaz, F., Eryılmaz, M., Esenli, F., Esenli, V., Özdemir, Z., Türker, A. ve Aydın, Ş., 2005. Edremit Körfezi ve Dikili Kanalı Güncel Cökellerinin Sedimantolojisi ve Jeokimyasi; TÜBİTAK destekli, proje no YDABCAG 100Y098, 152 sayfa, 2005, Mersin.

Yümün, Z.Ü., Meriç, E., Avşar, N., Nazik, A., Barut, İ. F., Yokeş, M. B., Sagular, E. K., Yıldız, A., Eryılmaz, M., Kam, E., Başsarı, A., Sonuvar, B., Dinçer, F., Baykal, K. ve Kaya, S., 2016. Meiofauna, microflora and geochemical properties of the Late Quaternary (Holocene) core sediments in the Gulf of Izmir (Eastern Aegean Sea-Turkey). İzmir Körfezi (İzmir-Doğu Ege Denizi) Journal of African Earth Sciences, 124, 383-408.

Yümün, Z. Ü., 2017. The effect of heavy metal pollution on foraminifera in the western Marmara Sea (Turkey). Journal of African Earts Sciences, 129, 346-365.

Zangger, E. ve Malz, H. 1989. Late Pleistocene, Holocene, and Recent ostracods from the Gulf of Argos, Greece. Courier Forschungsinstitut Senckenberg 113, 159-175 
